\title{
NUEVOS PLANTEAMIENTOS EN LA SEGURIDAD ENERGÉTICA DE LA UNIÓN EUROPEA Y OPCIONES EN EL MEDITERRÁNEO OCCIDENTAL
}

\author{
Soledad Segoviano ${ }^{1}$ \\ UNISCI / Universidad Complutense de Madrid (UCM)
}

\begin{abstract}
Resumen:
Durante la última década, la seguridad energética ha experimentado una escalada en la lista de prioridades estratégicas de la política energética y exterior de la UE. Las profundas transformaciones en el panorama energético global, impulsadas por los continuos avances tecnológicos, importantes desafíos geopolíticos, además de los imperativos derivados de la transición hacia un sistema energético descarbonizado, exigen la reevaluación de la estrategia de seguridad energética de la UE. Un proceso que, sin embargo, se encuentra condicionado por las tensiones derivadas de la necesidad declarada en favor de políticas de cooperación y coordinación reforzadas y el respeto por los intereses nacionales energéticos de los Estados Miembros. El objetivo de este trabajo se centra en analizar los desafíos que afronta la estrategia de seguridad energética de la UE en un mundo en transformación, identificando políticas y mecanismos que contribuyan a su fortalecimiento. La promoción y desarrollo de unas sólidas relaciones energéticas entre la UE y sus vecinos del sur del Mediterráneo representan una extraordinaria oportunidad para diseñar y alcanzar renovados objetivos estratégicos en beneficio de ambas regiones.
\end{abstract}

Palabras clave: Unión Europea, energía, seguridad energética, Mediterráneo.

Title in English: "New Approaches in the EU's Energy Security and Options for Western Mediterranean"

\begin{abstract}
:
Energy security has climbed the list of the European Union energy and foreign policy strategic priorities in the last decade. Deep transformations in the global energy landscape, triggered by technological advances, major geopolitical challenges and the imperatives of the transition to a low carbon energy system, are leading the EU to rethink its energy security strategy. A process that is driven, however, by the tensions between the declared need for closer cooperation and coordination and the respect of national energy interests of the EU Members states. The objective of this article is to analyze the challenges of the European energy security strategy in a changing global landscape and to discuss the policies and mechanisms in order to improve and strengthen it. The promotion of a better and deeper energy cooperation between the EU and its Mediterranean southern neighbours represents a singular opportunity to achieve newly defined strategic goals for both regions.
\end{abstract}

Keywords: European Union, energy,energy security, Mediterranean.

\section{Copyright (C) UNISCI, 2015.}

Las opiniones expresadas en estos artículos son propias de sus autores, y no reflejan necesariamente la opinión de UNISCI. The views expressed in these articles are those of the authors, and do not necessarily reflect the views of UNISCI

\footnotetext{
${ }^{1}$ La Dra. Soledad Segoviano Monterrubio es profesora de RRII en la Facultad de Ciencias de la Comunicación de la UCM e investigadora UNISCI y miembro del Foro Hispano-Argelino.

E-mail: soledad.s.monterrubio@ccinf.ucm.es.
}

http://dx.doi.org/10.5209/rev_RUNI.2015.n39.5181 


\section{Aproximación a la política energética exterior de la UE: implicaciones relacionadas con la seguridad energética}

La energía ocupa un lugar central en el actual panorama estratégico de la globalización y la interdependencia, donde los distintos actores internacionales se ven obligados a competir, de forma constante, en cambiantes escenarios de tensión geopolítica y geoeconómica en defensa de sus intereses específicos de seguridad energética ${ }^{2}$. Un concepto muy amplio, abierto y versátil, sobre el que no existe una definición consensuada o comúnmente aceptada, en la medida que afecta a distintos actores, con diferentes percepciones, desafíos y retos, en dinámicos e inestables contextos. En este sentido, para la UE, con un $53 \%{ }^{3}$ de dependencia de suministros energéticos procedentes del exterior, en un panorama condicionado por los imperativos del cambio climático y la generación de electricidad, la seguridad energética viene definida por la estrecha simbiosis entre seguridad en el suministro, reducción de la dependencia y medioambiente.

De acuerdo la Comunicación sobre la Estrategia Europea de Seguridad Energética ${ }^{4}$ de 2014, la UE importa actualmente el 53\% de la energía que consume. La dependencia del petróleo escala al 90\%; mientras que el gas natural alcanza el $66 \%$; por su parte, los combustibles sólidos y el combustible nuclear se sitúan en torno al 40\%. Rusia encabeza la lista de suministradores de petróleo, gas y combustibles sólidos con una aportación, para 2012 , del 34\%, 32\% y 26\%, respectivamente, de acuerdo con los datos del Statistical Pocketbook 20145, lo que implica una incuestionable dependencia energética respecto del gigante ruso, especialmente, en el caso del gas, donde los aprovisionamientos, vía gasoducto, representan el $86 \%$ de las importaciones, frente al 14\% del Gas Natural Licuado (GNL) para la EU-28, según los datos de 2013, aportados por Eurogas ${ }^{6}$. La factura energética exterior de la UE asciende a más de mil millones de euros diarios, en torno a 400 mil millones de euros en 2013, y representa más de una quinta parte de sus importaciones totales ${ }^{7}$. Todo, en un contexto de creciente demanda mundial de energía, para la que se prevé un incremento cercano al $30 \%$ para $2030^{8}$.

\footnotetext{
${ }^{2}$ La definición de seguridad energética, aportada por la Agencia Internacional de la Energía, como la capacidad de garantizar el suministro energético a unos precios razonables, atendiendo a consideraciones medioambientales, resulta cuestionable. En un contexto de interdependencia global, esta definición se centra, exclusivamente, en el lado de los consumidores de energía, desatendiendo, por tanto, otras variables relevantes como las necesidades de seguridad en la demanda que exigen los países productores; los desafíos asociados a los nacionalismos energéticos de países productores y consumidores; la participación en el juego geopolítico de actores no estatales violentos; los riesgos derivados de posibles interrupciones en el suministro; los impactos derivados de la incorporación a la demanda de energía de los países emergentes como China e India; la situación de exclusión/pobreza energética para millones de personas; o los desafíos de sostenibilidad y cambio climático, entre otros.

${ }^{3}$ Comisión Europea, COM (2014) 330 final, 28 de mayo de 2014: Estrategia Europea de la Seguridad Energética, p. 2, en

http://www.europarl.europa.eu/meetdocs/2014 2019/documents/com/com com(2014)0330/com com(2014)03 30 es.pdf.

Ibíd.

${ }^{5}$ European Commission, EU energy in figures. Statistical Pocketbook, 2014, p. 27, disponible en: https://ec.europa.eu/energy/sites/ener/files/documents/2014_pocketbook.pdf.

${ }^{6}$ Eurogas, Statistical Report 2014, p. 7, en

http://www.eurogas.org/uploads/media/Eurogas_Statistical_Report 2014.pdf.

${ }^{7}$ Comisión: Estrategia Europea Seguridad Energética, op., cit., pp. 2-3

${ }^{8}$ Eurogas, Long Term Outlook for Gas Demand and Supply 2007-2030, June 5, 2010, p. 5, en http://www.eurogas.org/uploads/media/Statistics_Eurogas_LT Outlook 2007-2030 Final 25.11.10.pdf;

estos datos se ven matizados, sin embargo, en el Long Term Outlook for gas to 2035, p.3, donde se mantiene la previsión de incremento de la demanda de gas en un 30\% para 2035, sólo en el escenario denomidado The Environmental Case, donde se anticipa un reequilibrio del mix energético con aumento de la participación de las
} 
La UE se configura, así, como uno de los principales consumidores e importadores de energía a escala global, cuyas principales fuentes de suministro se encuentran en la vecindad europea, más concretamente, en la región dominada por la cuenca del Mediterráneo, un espacio rico en recursos, hidrocarburos y renovables, que cuenta con países de tránsito y corredores estratégicos vitales para la UE y para el sistema energético mundial, en la medida que conectan los flujos energéticos procedentes del Norte de África, Golfo Pérsico, Rusia, Asia Central y Europa.

La UE se enfrenta, por tanto, a importantes retos en el campo de la energía, en general, y de la seguridad energética, en particular. La dependencia de las importaciones de hidrocarburos; la necesidad de diversificación en cuanto a fuentes y orígenes; los volátiles precios de la energía; el aumento sostenido de la demanda energética mundial; los riesgos, desafíos y amenazas que afectan a países productores y en tránsito, incrementando, con ello, la vulnerabilidad física de los países importadores de la UE; la necesidad derivada de reforzar, a la vez que reinventar, la dimensión externa de la política energética comunitaria; los desafíos asociados al cambio climático; la limitada eficacia de las políticas de ahorro y eficiencia energéticas; los altos costes de inversión de la industria de las energías renovables, así como la incuestionable necesidad de mejorar la integración e interconexión de los mercados energéticos europeos, representan algunas de las cuestiones más relevantes que vienen marcando la agenda energética de la UE.

Para hacer frente a esta preocupante situación de dependencia y vulnerabilidad, la UE, fundamentalmente, a través de la Comisión Europea (CE), ha venido desarrollando un ambicioso y dinámico proceso de formulación política y desarrollo de propuestas, iniciativas y proyectos al servicio de la seguridad energética, centrados en: a) la progresiva reducción de la dependencia externa de la UE; b) la garantía del abastecimiento energético sin interrupciones en el suministro (seguridad en el suministro; y, c) la obligada adaptación a las consecuencias negativas asociadas al cambio climático.

Estos tres objetivos prioritarios, definidos de forma progresiva a partir del año 2000 , con la publicación del Primer Libro Verde Hacia una estrategia europea de seguridad en el abastecimiento energético, donde se alertaba sobre la extrema dependencia europea respecto de Rusia, se han ido articulando, a lo largo de estos últimos años, en torno a cuatro grandes ejes estratégicos: 1) diversificación en el origen de las importaciones; 2) fomento de las interconexiones de gas y electricidad; 3) impulso a las medidas de ahorro y eficiencia energética; y, 4) fomento de las energías renovables, contempladas éstas, como alternativa de autoabastecimiento europeo y fuentes de energía limpia frente al desafío del cambio climático.

Estos cuatro ejes conforman los pilares básicos sobre los que se asienta la compleja e intrincada red de medidas, líneas de actuación y proyectos que dan forma a la política energética de la UE en su dimensión externa, y, más concretamente, a la estrategia de seguridad energética de la Unión, en la medida que, debe convivir con las políticas de seguridad energéticas de los 28 Estados Miembros (EM).

renovables para la generación de electricidad, acompañado de un crecimiento económico con alto grado de innovación tecnológica, aplicada a la eficiencia energética; por su parte, las previsiones experimentan un descenso en la demanda, situado en el 24\%, para el escenario denominado Low Development Case, donde el consumo de gas resulta menos competitivo en Europa como consecuencia de las dinámicas de competición geopolítica, una ineficaz política medioambiental, un frágil desarrollo industrial y un limitado progreso en eficiencia energética, en

http://www.eurogas.org/uploads/media/Eurogas_Brochure_Long-Term_Outlook for_gas to_2035.pdf. 
Y, es que, si bien el Tratado de Lisboa, en el Titulo XXI, sobre Energía, Artículo 194, contempla nuevas competencias energéticas para la Unión, reforzando el papel de la Comisión en materia de energía, lo cierto es que en un malabarismo de ambigüedad, al servicio de los intereses estatales, también se mantiene, y se prioriza, de acuerdo con el punto 2 del citado artículo 194, el derecho de los EMs a determinar las condiciones de explotación de sus recursos energéticos, sus posibilidades de elegir entre distintas fuentes de energía y la estructura general de su abastecimiento energético; punto 2, en el que, por otra parte, también se hace referencia a la letra c del apartado 2 del artículo 192, del Título XX, sobre Medioambiente, donde se contempla un procedimiento de toma de decisiones blindado por la unanimidad para todas las medidas que afecten de forma significativa a la elección por los EM entre diferentes fuentes de energía y a la estructura general del abastecimiento energético. Y, esto, a pesar de que entre los objetivos de política energética de la UE, de nuevo, en el mencionado artículo 194, esta vez, en su punto 1, letra b, se reconoce la importancia de garantizar la seguridad en el abastecimiento energético de la Unión; además de otras medidas, con espíritu de solidaridad entre los EM, como: a) garantizar el funcionamiento del mercado de la energía; c) fomentar la eficiencia y el ahorro energético, así como el desarrollo de energías nuevas y renovables; y d) fomentar la interconexión de las redes energéticas.

De esta forma, el Artículo 194 representa un compromiso cuidadosamente construido para para garantizar, de acuerdo con el punto 2, la soberanía nacional de los EM en relación con la composición del mix energético, la elección de explotación de recursos naturales, así como el control y la gestión de los impuestos de energía, tres componentes claves de cualquier política energética; $y$, al mismo tiempo, fomentar las competencias compartidas con la Unión en otras áreas, contempladas en el punto 1 del mencionado Artículo.

Por tanto, en la práctica, a pesar de las buenas intenciones y de la retórica formal del discurso, en sintonía con las pautas de la Comisión, los EM siguen valorando la seguridad energética en clave geopolítica, al servicio de los intereses nacionales de seguridad en el suministro, y no en términos comunitarios. En este sentido, la acomodación de las distintas preferencias de los Estados, de acuerdo con intereses específicos divergentes, -geográficos, políticos, económicos, empresariales-, resulta extremadamente complicada a la hora de diseñar y aplicar una política energética exterior europea.

La UE goza de competencias muy relevantes para sus intereses geopolíticos, pero no dispone de la capacidad para actuar con independencia de los Gobiernos de los EM. Son los EM, en el ejercicio de sus respectivas políticas exteriores y energéticas, los que dirigen las riendas de una pretendida política energética de la UE que, en el mejor de los casos, podría calificarse como limitada, fragmentada y divergente, en la medida que los compromisos bilaterales de los EM con los países suministradores de energía prevalecen frente a la aproximación comunitaria de la UE, limitando la proyección internacional efectiva de un auténtico mercado de la energía europeo.

\subsection{La política exterior europea al servicio de la seguridad en el suministro: la importancia del espacio de vecindad}

De todos modos, y a pesar de su relativo protagonismo, la Comisión ha venido desarrollando, desde 2006, un notable esfuerzo en torno a los cuatro grandes ejes estratégicos, anteriormente mencionados, al servicio del objetivo de europeización de la política energética exterior. Una cobertura política, en la que, en última instancia, se percibe el interés de la Comisión por integrar la estrategia de seguridad energética en la política exterior europea. 
De esta forma, en la primavera de 2006, la Comisión daba a conocer el segundo Libro Verde $^{9}$, donde se pretendía compatibilizar seguridad energética y sostenibilidad. Los objetivos de este segundo Libro Verde se verán concretados en el documento An external policy to serve Europe's energy interests ${ }^{10}$, elaborado por Javier Solana, en marzo de 2006, donde se insistirá en la necesidad de conciliar las dimensiones interna y externa de la política comunitaria para garantizar la seguridad en el suministro, mediante la promoción de paternariados energéticos con terceros países y el desarrollo de infraestructuras para el transporte de energía, tanto en los países productores como en los países de tránsito ${ }^{11}$.

Así, la maquinaria de política exterior de la UE, activada por la Comisión, al servicio de una estrategia europea de seguridad energética, procedió a la definición de los corredores energéticos, que conectan la UE con las principales zonas tránsito y suministro, para trazar, sobre la base de estas rutas estratégicas, la compleja red de acuerdos, tratados, proyectos, iniciativas, asociaciones..., con terceros países, a fin de reforzar la interconexión energética y garantizar las inversiones en infraestructuras.

Estos macrocorredores energéticos, definidos en el proyecto europeo REACCESS (Risk of Energy Availability: Common Corridors for Europe Supply Security) ${ }^{12}$, de acuerdo con una óptica geopolítica en la optimización de las rutas del espacio de vecindad europeo, son seis y discurren, en función de su origen y en el sentido de las agujas del reloj, de acuerdo con el siguiente mapa, trazado por Gonzalo Escribano ${ }^{13}$ : 1) corredor intraeuropeo, procedente del Mar del Norte y Noruega; 2) procedente de Rusia, a través de Turquía y del norte y centro de Europa; 3) el procedente de Asia Central, a través de Turquía y Rusia; 4) el procedente del Golfo Pérsico, a través de Oriente Medio y/o Turquía y el Mediterráneo, o, alternativamente, rodeando África; 5) procedente de África del Norte, atravesando también el Mediterráneo; y 6) el que transcurre por el Atlántico desde África Occidental para conectar con el sur de Europa y el Mediterráneo por el Estrecho de Gibraltar. No se considera el procedente de América Latina, pues sólo resulta relativamente relevante para España. Como podemos comprobar, tres corredores $(4,5$ y 6$)$ afectan directamente a la vecindad del Mediterráneo.

Establecidos los mapas energéticos, la UE procederá al diseño y establecimiento de los oportunos mecanismos de cooperación de política exterior, que adolecen, sin embargo, de una importante contradicción, a saber: la pretensión de Bruselas de exportar un acervo comunitario basado en las reglas de la democracia y el libre mercado, cuando, en realidad, se priorizan los intereses de geopolítica energética, vinculados a los intereses nacionales de los EM, donde, claramente, prima la aproximación bilateral, provocando, así, distorsiones,

\footnotetext{
${ }^{9}$ Comisión Europea, COM (2006) 105 final, Marzo de 2006: Libro Verde. Estrategia europea para una energía sostenible, competitiva y segura.

${ }^{10}$ Paper from Commission/SG/HR for the European Council: An external policy to serve Europe's interests, p.1, en: http://ec.europa.eu/dgs/energy transport/international/doc/paper solana sg energy en.pdf.

${ }^{11}$ Ibid., p. 2

12 Escribano Francés, Gonzalo: "Entre el mercado y la geopolítica: seguridad de abastecimiento y corredores energéticos en la UE", Economía de la energía, n ${ }^{\circ}$ 842, (Mayo-Junio 2008), p. 40, en http://reaccess.epu.ntua.gr/LinkClick.aspx?fileticket=PtdbCYRWVCI\%3D\&tabid=761\&mid=1532.

Para obtener más información sobre REACCESS, ver: http://reaccess.epu.ntua.gr/. De acuerdo con Escribano, REACCESS, del VII Programa Marco de la CE, trata de analizar las respuestas políticas ante los escenarios energéticos de la UE, considerando aspectos técnicos, ambientales y geopolíticos para todas las fuentes de energía e infraestructuras relacionadas. REACCESS trata de superar las limitaciones de ENCOURAGED (Energy Corridor Optimisation for European Markerts of gas, electricity and hydrogen), el anterior proyecto europeo, iniciado en 2005, destinado a identificar los corredores energéticos económicamente óptimos entre la UE y sus países vecinos.

${ }^{13}$ Ibid., p. 40.
} 
resistencias, rechazos y desconfianzas en los dos ámbitos de la estrategia de seguridad energética, interno y externo, y, en definitiva, la escasa efectividad del modelo.

En el marco de estas pugnas y confrontaciones, y a pesar de ellas, la UE, vía instituciones, ha seguido su labor. Entre las incontables iniciativas puestas en marcha por la Comisión de cara a incrementar la seguridad energética en la vecindad europea cabe destacar, entre otras: el Tratado de la Comunidad de la Energía del Sudeste Europeo, para asegurar el corredor estratégico procedente de Rusia, Asia Central y Oriente Medio; la propuesta de extensión del Tratado de la Comunidad de la Energía a la Ribera Sur del Mediterráneo, para establecer un Mediterranean Ring, que permita la interconexión de los sistemas energéticos del Magreb, y de éstos con la UE mediterránea ${ }^{14}$, a la que, además, se une el Plan Solar Mediterráneo, enmarcado dentro de la iniciativa francesa Unión por el Mediterráneo ${ }^{15}$; también cabe destacar la Política Europea de Vecindad $(\mathrm{PEV})^{16}$, con la inclusión de Azerbaiyán, dada su posición estratégica y su riqueza en recursos energéticos; la Iniciativa Bakú, para incorporar a los países de la región del Caspio en un intercambio de inversiones en infraestructuras, a cambio de garantías en el suministro energético; la Estrategia de la UE para África, que incluye una asociación para fomentar la interconexión de infraestructuras ${ }^{17}$; el Acuerdo de Cooperación con los países del Consejo de Cooperación del Golfo (CCG); el diálogo energético UE-Rusia; el Memorándum de Entendimiento entre la UE y Ucrania; el Documento de Estrategia Regional de Ayuda a Asia Central ${ }^{18}$... Además de un sinfín de iniciativas relacionadas de forma específica con la vecindad del Mediterráneo, a las que nos referiremos más adelante.

\subsection{Estrategia de seguridad energética v cambio climático}

Además de la seguridad en el suministro, la preocupación por el cambio climático ${ }^{19}$ representa otro de los grandes ejes sobre los que se articula la estrategia de seguridad energética europea. Así, el 10 de enero 2007, en el marco de la Presidencia alemana, la Comisión publicaba una nueva comunicación ${ }^{20}$, titulada Una politica energética para Europa, adoptada, en el mes de marzo en la Conclusiones del Consejo Europeo, con el fin de encaminar las actuaciones de la UE por la senda de la lucha contra el cambio climático. El documento, conocido como las tres "20s" para el horizonte de 2020, propone objetivos a largo plazo, centrados en la reducción en un $20 \%$, en comparación con los niveles de 1990, de las emisiones de $\mathrm{CO} 2$; el aumento de la participación de las energías renovables en un $20 \%$; además de la reducción, también en un $20 \%$, del consumo de energía, objetivos destinados, en definitiva, a reducir la dependencia en los combustibles fósiles, preservar el medioambiente y

\footnotetext{
${ }_{15}^{14}$ Escribano, "Entre el mercado y la geopolítica...", op., cit., p. 41.

15 Marquina Barrio, Antonio: "La declaración conjunta en la Cumbre de París para el Mediterráneo. Un documento claramente mejorable en asuntos de seguridad", UNISCI Discussion Papers, No19 (Enero/January 2009).

${ }^{16}$ La Política Europea de Vecindad se diseñó entre 2002 y 2004 ante la necesidad de coordinar los objetivos de las numerosas y dispersas relaciones mantenidas por la UE con los países vecinos ante la inminente incorporación de los países de Europa Central y Oriental en 2004. La PEVse mueve en un amplio espectro que abarca a países vecinos del Este, caucásicos y mediterráneos.

17 Youngs, Richard: "Europe's external energy policy: between geopolitics and the market", Center for European Policy Studies Working Document, $\mathrm{N}^{\mathrm{o}} 278$ (November 2007), pp. 2 y 3 , en http://fride.org/download/WP_CEPSEnergy_ENG_nov07.pdf.

18 Denison, Michael: "La UE y Asia Central: comercializar la relación energética", EU-Central Asia Monitoring, Documento de Trabajo 02, (Julio de 2009), p. 2, en http://fride.org/download/EUCAM WP2_UE_Central_Asia_ESP agust09.pdf.

${ }^{19}$ En este sentido, el fomento de la eficiencia energética se configura como una herramienta para combatir el cambio climático.

${ }^{20}$ Comisión Europea: Una política energética para Europa; Comisión Europea: COM (2007)1 final. Consejo Europeo: Conclusiones de la Presidencia, 8-9 de marzo 2007.
} 
propiciar el desarrollo tecnológico. En este documento, además, la UE se compromete a ayudar a los países en desarrollo a crear servicios energéticos descentralizados, poco costosos, fiables y sostenibles, fomentando la inversión en energías renovables y en la nueva generación de tecnologías energéticas limpias ${ }^{21}$, en favor de una energía segura, competitiva y sostenible ${ }^{22}$.

De acuerdo con esta estrategia, desde 2007, la UE ha destinado importantes partidas del presupuesto europeo ${ }^{23}$ a proyectos y programas relacionados con el clima en países en desarrollo, sobre la base de acuerdos bilaterales y programas multilaterales gestionados por distintas organizaciones como Naciones Unidas; y a través de distintos instrumentos regionales como EU-Africa Infraestructure Trust Fund, The Neighbourhood Investment Facility, The Latin America Investment Facility, The Caribbean Investment Facility, Investment Facility for Central Asia..., entre otros. Todos ellos, al servicio del fomento y desarrollo de infraestructuras críticas e innovación tecnológica.

Estas iniciativas se verían reforzadas, a partir de enero de 2008, con la puesta en marcha de un importante "paquete energético", centrado en diferentes prioridades como: el fortalecimiento y ampliación del régimen de comercio de derechos de emisión, con el propósito de alcanzar un $21 \%$ de reducción de cuotas de emisión, respecto a los niveles de 2005; la promoción, el desarrollo y el uso seguro de la captura y almacenamiento de carbono (CAC), un complejo dispositivo de tecnologías que permiten capturar y almacenar en el subsuelo el dióxido de carbono, emitido en los procesos industriales; fomento de medidas y políticas destinadas a abordar las emisiones de los transportes; o el incremento sustancial del presupuesto de investigación y desarrollo destinado a medioambiente, energía y transporte.

Así, la preocupación por el cambio climático y su impacto en la política de seguridad europea quedarían expresados, en marzo de 2008, en el denominado Documento Solana, Climate change and International Security ${ }^{24}$, un documento conjunto elaborado por Alto Representante, Javier Solana, y la Comisión Europea, donde el cambio climático se catalogaba como threat multiplier, por lo que resultaba necesario situarlo en el epicentro de la política de seguridad europea. De esta forma, la seguridad energética concebida hasta entonces sobre la base de un enfoque reduccionista, centrado de forma prioritaria en las relaciones estratégicas con países productores de hidrocarburos, debería, según el Documento,

\footnotetext{
${ }^{21}$ Esta iniciativa se encuentra estrechamente ligada a la Comunicación de la Comisión, también publicada el 10 de enero de 2007, sobre la necesidad de Limitar el calentamiento mundial a $2^{\circ} \mathrm{C}$, medidas necesarias hasta 2020 y después: COM (2007) 2 final; a su vez, ambas Comunicaciones representan la continuación de la Comunicación de 2005, Estrategia sobre el cambio climático: bases para la estrategia, que sentaba las bases sobre una futura estrategia contra el cambio climático: COM (2005) 35.

${ }^{22}$ Dentro de este marco de actuación, en noviembre de 2007, la UE decidía poner en marcha el denominado Plan Europeo de Estrategia Energética, Strategic Energy Technololgy Plan (SET-Plan), que contempla un apoyo decidido a los proyectos de innovación tecnológica aplicados a la efíciencia energética y a las energías renovables mediante dotaciones económicas adicionales a la investigación y a través de diversos mecanismos de coordinación como la denominada Europe Energy Research Alliance (EERA).

${ }^{23}$ El compromiso de la UE con la ayuda a los países en desarrollo en la lucha contra el cambio climático y la preservación del medioambiente, a partir de 2007 hasta la actualidad, queda demostrado en los siguientes documentos donde se pueden constatar las contribuciones del presupuesto europeo destinadas a proyectos climáticos en los países en desarrollo, canalizados a través de diversas iniciativas y mecanismos. Ver: COM (2014) 689 final: Progress to achieving the Kyoto and EU 2020, objectives, 28 de octubre de 2014, pp. 20-21, en: http://ec.europa.eu/transparency/regdoc/rep/1/2014/EN/1-2014-689-EN-F1-1.Pdf; y también: Council of the European Union: EU submission 2014 on strategies and approaches for scaling up climate finance, 29 de septiembre de 2014, p.4, en http://ec.europa.eu/clima/policies/finance/docs/eu strategies and approaches en.pdf.

${ }_{24}$ Climate Change and International Security, Paper from the High Representative and the European Commission to the European Council, 14 de marzo de 2008, en

http://www.consilium.europa.eu/uedocs/cms_data/docs/pressdata/en/reports/99387.pdf.
} 
ser abordada desde una perspectiva más amplia con el fin de integrar las inevitables consecuencias estratégicas del cambio climático en la política de seguridad de la Unión, enfrentando los retos y desafíos medioambientales de la denominada seguridad climática. Este planteamiento tendría su traslación en la Revisión de la Estrategia Europea de Seguridad, de diciembre de 2008, donde la seguridad energética y el cambio climático serían concebidos como desafíos globales y amenazas estratégicas ${ }^{25}$. También, en diciembre de 2008, coincidiendo con el final de la Presidencia francesa, el Paquete Energía-Cambio Climático recibiría el visto bueno de las instituciones comunitarias para entrar en vigor en junio de 2009.

Así pues, el Paquete Energía-Clima de 2009 quedaría conformado en seis actos legislativos, cuatro Directivas, un Reglamento y una Decisión ${ }^{26}$, relativos al fomento del uso de energía procedente de fuentes renovables; el perfeccionamiento y ampliación del comercio de los gases de efecto invernadero; la reducción de las emisiones de gases de efecto invernadero; el almacenamiento geológico de dióxido de carbono; el control y la reducción de las emisiones de gases de efecto invernadero derivadas de la utilización de combustibles en el transporte por carretera y en la navegación interior; así como normas de comportamiento en materia de emisiones CO2 de turismos nuevos. Medidas, que colocaban a la UE a la cabeza de la lucha contra el cambio climático, en un contexto internacional marcado por las grandes expectativas suscitadas ante la inminente celebración, en Copenhague, de la XV Conferencia Internacional sobre Cambio Climático, prevista para diciembre de ese año.

\subsection{Seguridad en el suministro v cambio climático: nuevas medidas para incrementar la seguridad energética europea}

Si bien las iniciativas desarrolladas entre 2007 y 2009 resultan encomiables frente a los desafíos del cambio climático, sus metas se sitúan en el marco temporal del largo plazo, por lo que, en noviembre de 2008, la Comisión publicaba un nuevo documento estratégico, el denominado Second Strategic Energy Review ${ }^{27}$, (SSER) con el fin de enfrentar los desafíos relacionados con la dependencia, la vulnerabilidad y el abastecimiento, en el corto plazo, mientras se seguía avanzando en los objetivos de eficiencia y cambio climático establecidos en los escenarios de futuro.

Este importante documento recoge la estrategia europea de seguridad energética, desplegada sobre la base de cinco grandes líneas de actuación: 1) la mejora de infraestructuras energéticas de interconexión y el fomento de las estrategias de diversificación de los suministros; 2) el impulso de las relaciones exteriores de la UE; 3) el mantenimiento de stocks de petróleo y gas, junto al desarrollo mecanismos de solidaridad entre los Estados Miembros, en caso de graves interrupciones en los suministros; 4) adopción de propuestas de eficiencia

\footnotetext{
${ }^{25}$ Providing security in a changing world, 11 de diciembre de 2008, en http://www.consilium.europa.eu/uedocs/cms data/docs/pressdata/en/reports/104630.pdf.

${ }^{26}$ Reglamento (CE) 443/2009 en materia de emisiones de turismo; Directiva 2009/28/CE relativa al fomento del uso de energía de fuentes renovables; Directiva 2009/29/CE, que perfecciona y amplía el régimen comunitario de comercio de derechos de emisión de gases de efecto invernadero; Directiva 2009/30 CE para controlar y reducir las emisiones de gases de efecto invernadero; Directiva 2009/31/ CE relativa al almacenamiento geológico de dióxido de carbono; Decisión 406/2009 sobre el esfuerzo de los Estados Miembros para reducir sus emisiones de gases de efecto invernadero a fin de cumplir los compromisos adquiridos hasta 2020. Puede consultarse en: Diario Oficial de la Unión Europea, L140, 5 de junio de 2009, accesible en http://eurlex.europa.eu/legal-content/ES/ALL/?uri=OJ:L:2009:140:TOC.

${ }^{27}$ European Commission (Memo): EU Energy Security and Solidarity Action Plan: Second Strategic Energy Review, en: http://ec.europa.eu/energy/strategies/2008/doc/2008 11 ser2/strategic energy review memo.pdf; Ver también: DELEGATION OF THE EUROPEAN COMMISSION TO THE US: Ramping up energy security: the EU energy and climate change program, en http://www.eurunion.org/News/euNewsletters/EUFocus/2009/EUFocus-EnergySecur-11-09.pdf.
} 
energética; y, 5) desarrollo de los recursos energéticos propios ${ }^{28}$. En este sentido, cabe destacar el capítulo referido a las conexiones internacionales, donde la Comisión identifica una serie de infraestructuras prioritarias para garantizar la diversificación en el origen y la seguridad en el suministro en la vecindad este y sur, donde ya destacan los recurrentes Corredor Sur del Gas, contemplado para reducir la dependencia gasista de Rusia y el Anillo energético del Mediterráneo para reforzar las interconexiones gasistas y eléctricas entre ambas orillas de la cuenca mediterránea, de acuerdo con la estrategia de diversificación de la UE para reducir la dependencia energética de Rusia.

Ya en 2010, y bajo la cobertura legal del Tratado de Lisboa, la Comisión se centrará en la consecución de los objetivos fijados para 2020, trazando su estrategia en dos Comunicaciones presentadas a finales de año. Así, el 10 de noviembre, con la Comunicación titulada Energía 2020: Estrategia para una energía competitiva, sostenible y segura ${ }^{29}$, la Comisión describe la estrategia energética para el horizonte de 2020, articulada en torno a cinco prioridades, por otra parte, ya perfiladas en la estrategia de 2007: limitación en el consumo de energía; establecimiento de un mercado paneuropeo integrado de la energía; suministro de energía fiable y segura a precios asequibles; desarrollo de tecnologías innovadoras relacionadas con la energía; y, por último, reforzamiento de los vínculos exteriores con el fin de fomentar la participación de los países vecinos en la consolidación del mercado interior.

Precisamente, al servicio de estos objetivos prioritarios, el 17 de noviembre, la Comisión presentará su Comunicación sobre Las prioridades de la infraestructura energética a partir de 2020: esquema para una red energética europea integrada ${ }^{30}$ con el fin de coordinar y optimizar el desarrollo continental de las redes, al servicio de la política energética y de la estrategia económica de la UE. El desarrollo de la infraestructura europea permitirá la materialización del mercado interior e incrementará la seguridad en el abastecimiento, posibilitando la integración de las fuentes renovables y el uso inteligente de la energía. Sin embargo, la aplicación de estas estrategias y la consecución de estos objetivos no estarán exentas de dificultades, en la medida que exigirán un elevado flujo de inversiones en un, cada vez más, preocupante contexto de crisis financiera y económica, donde la UE se verá obligada a interactuar en un escenario energético global en acelerado proceso de cambio, inesperadamente adverso, para los intereses de seguridad energética europeos. Un panorama cambiante, que se había ido gestando desde la crisis financiera de 2008, con un punto de inflexión en el año 2011.

\section{La seguridad energética de la UE en el marco de las transformaciones en el panorama energético global: nuevos retos v desafíos}

Así, la crisis económica y financiera combinada, entre otras cuestiones, con el extraordinario impulso público a las energías renovables como fuentes de generación de electricidad, en virtud de las directrices del Paquete Clima y Energía, derivó, igualmente, en interesantes contradicciones. Y, es que, si bien las consecuencias positivas se articularon en torno a la mejora en la eficiencia y el descenso en el consumo energético; en el balance negativo, debemos anotar los considerables incrementos en los precios de la electricidad repercutidos a

\footnotetext{
${ }^{28}$ Para un análisis más exhaustivo sobre los objetivos especificados, así como otros documentos de interés relevante, se recomienda muy especialmente acceder a los links del siguiente documento publicado por la Comisión: European Commission, Second Strategic Energy Review: Securing our energy future, November 2008, en: http://ec.europa.eu/energy/strategies/2008/2008 11 ser2 en.htm.

${ }^{29} \mathrm{COM}(2010) 639$ final.

${ }^{30} \mathrm{COM}(2010) 677$ final.
} 
los consumidores $^{31}$; así como los inevitables desajustes derivados de un insuficiente desarrollo de las infraestructuras de interconexión de gas y electricidad, capaces de absorber los incrementos en la generación de las energías renovables.

Asimismo, los altos precios del barril de petróleo, por encima de los $80 \$$, entre 2007 y 2014, como consecuencia de la inestabilidad geopolítica en las regiones productoras y la creciente demanda de los países emergentes, vinieron a impulsar las inversiones en exploración y explotación de los combustibles fósiles (recursos no convencionales, explotaciones offshore en aguas ultraprofundas), dando lugar al descubrimiento de importantes reservas en países del Este de África, del Mediterráneo Oriental y, por supuesto, al despegue de la revolución del shale gas (oil) en Estados Unidos ${ }^{32}$. Paralelamente a estos descubrimientos, el prolongado descenso de la producción de combustibles fósiles en seno de la UE, como consecuencia de la progresiva transición hacia la descarbonización, unido a la segunda crisis de Ucrania, en 2009, provocaron el efecto no deseado de incrementar, aún más, los índices de dependencia de las importaciones de hidrocarburos, fundamentalmente de Rusia, con el consiguiente aumento de la factura energética en un contexto de crisis.

Además, en marzo de 2011, el desastre nuclear de Fukushima vendría a incorporarse como variable a esta dinámica de transformación, renovando el debate sobre las garantías de seguridad de las centrales nucleares y la conveniencia de su aportación para la generación de electricidad. Aunque, sin duda, las repercusiones más relevantes derivadas del accidente en la central nuclear japonesa, en especial para los intereses de seguridad energética de la UE-28, se harían visibles en la decisión unilateral de Alemania de acelerar su "apagón" nuclear; y, ante todo, en las alteraciones de los mercados energéticos del GNL, como consecuencia del fuerte aumento en la demanda de los países asiáticos, con el consiguiente incremento de los precios de las importaciones de este gas. La interactuación de estas variables situaría a la UE en la confluencia de desconcertantes paradojas.

La primera a considerar viene derivada de una comparativa: el notable incremento, en 2011, de la demanda global de gas natural, especialmente el GNL en todos los continentes, excepto en la UE, donde el consumo de gas natural cayó un $10 \%$ respecto de los valores de $2010^{33}$, tendencia que se ha venido confirmando, de forma más o menos constante, en años sucesivos, con un descenso ligeramente superior al $11 \%$, en el consumo de gas natural en

\footnotetext{
${ }^{31}$ De acuerdo con los datos referidos al segundo semestre del año 2014 y publicados por Eurostat, el pasado 27 de mayo de 2015, España es el cuarto país más caro en los precios de la electricidad en euros corrientes, sólo por detrás de Dinamarca, Alemania e Irlanda. Los precios de la electricidad de los hogares de los EU28 se mueven en un amplio margen, entre los 9 euros por cada 100 kilovatios hora (kWh) de Bulgaria, hasta los 30,4 de Dinamarca; 29,7 de Alemania; 25, 4 de Irlanda; y 23,7 de España, seguida de cerca por Chipre $(23,5)$ e Italia $(23,4)$. Se da la circunstancia de que los países con los precios de la electricidad más caros, como Dinamarca, han realizado una importante apuesta por las renovables. En el caso concreto de España, además de las subvenciones, es importante considerar la sobrecapacidad en la producción del sistema en un contexto de contención de la demanda. Es preciso tener en cuenta que el anterior Gobierno de Zapatero fijó unas generosas primas a las renovables. El efecto llamada para las empresas eléctricas y los grandes fondos de inversión internacionales fue inmediato, viendo la posibilidad de transformar una política de ayuda concebida, en principio, para fomentar el desarrollo de una tecnología rentable y respetuosa con el medio ambiente, en un rentable activo financiero. Consultar Eurostat Newsrelease, 27 May 2015, en

http://ec.europa.eu/eurostat/documents/2995521/6849826/8-27052015-AP-EN.pdf/4f9f295f-bb31-4962-a7a9b6c4365a5deb.

${ }^{32}$ Andoura, Sami y Vinois, Jean Arnold: "From de European Energy Community to the Energy Union, a policy proposal for the short and long term", Notre Europe, Jacques Delors Institute, Studies and Reports, (January 2015), p. 32, en: http://www.institutdelors.eu/media/energyunion-andouravinois-jdi-jan15.pdf?pdf=ok.

${ }^{33}$ Badida, Jozef; "A golden age of natural gas in Europe?", Journal of Energy Security, 17 April 2013, p.1, en: http://ensec.org/index.php?option=com_content\&view=article\&id=440:a-golden-age-of-natural-gas-ineurope\&catid=135:issue-content\&Itemid=419.
} 
2014, con el consiguiente impacto en las importaciones netas de este gas, vía GNL y gasoducto, que descendieron en un $8 \%$ para el mismo año de referencia ${ }^{34}$.

Varias razones explican esta tendencia: la caída en la demanda de electricidad generada en las plantas de ciclo combinado de gas, como consecuencia de los efectos adversos de la crisis económica; el aumento en la producción de electricidad, gracias al progresivo incremento de las aportaciones de las energías renovables ${ }^{35}$, sustentadas con generosas políticas de incentivos fiscales ${ }^{36}$; inviernos más templados, como consecuencia de la subida del promedio de las temperaturas; y, por supuesto, el uso de carbón, en sustitución del gas natural, destinado a la generación de electricidad. Y es aquí donde nos encontramos con la segunda paradoja, en la medida que un sistema energético como el de la Unión, que viene fijando sus objetivos en la descarbonización a medio y largo plazo en su lucha contra el cambio climático ${ }^{37}$, con progresivos aumentos en la aportación de las renovables y la innovación tecnológica, se sustenta en incrementos en el consumo de carbón para la generación de electricidad en el corto plazo.

A su vez, esta paradójica situación se deriva de la interrelación de varias dinámicas, que se entrecruzan de forma simultánea en el marco de los mercados energéticos. En primer lugar, en un mercado fragmentado del gas, donde los altos precios del GNL, -como consecuencia del tirón de la demanda de los importadores asiáticos, dispuestos a pagar, a raíz del desastre de Fukushima, $16 \$$ por $\mathrm{MBbtu}^{38}$-, interactúan con los bajos precios norteamericanos, que oscilan en torno a los $4 \$$ por MBtu para 2013, o los 2,69\$, ya en septiembre de $2015^{39}$, generando, como es lógico, importantes diferenciales, que impactan de forma negativa en la fijación de los precios spot del gas europeos, algo más altos y, sobre todo, sometidos a constantes fluctuaciones, entre 7-10-12\$ por $\mathrm{MBtu}^{40}$.

Asimismo, la escalada en los precios spot de gas asiáticos y europeos ha venido acompañada de un descenso en los precios del carbón, como consecuencia del aumento de los suministros procedentes de Estados Unidos y Canadá, donde la generación de electricidad de la industria se sustenta, cada vez más, en las aportaciones del barato y abundante shale gas, lo que genera un excedente de carbón a bajo precio que, en gran medida, va destinado a la exportación hacia los mercados europeos, donde, a su vez, los bajos precios del $\mathrm{CO} 2^{41}$, como consecuencia del superávit de los derechos de emisión, está provocando la progresiva sustitución del gas por el carbón en la producción de electricidad, atendiendo a

\footnotetext{
${ }^{34}$ BP Statistical Review 2015: The EU energy market in 2014, en

http:/www.bp.com/content/dam/bp/pdf/Energy-economics/statistical-review-2015/bp-statistical-review-ofworld-energy-2015-eu-insights.pdf.

${ }^{35}$ Consultar los progresivos incrementos de aportación de las energías renovables en la generación de electricidad en la UE-28, desde 2004, con un 14,3\% de aportación, a 2013, con un 25,4\%, en http://ec.europa.eu/eurostat/statisticsexplained/index.php/File:Share of energy from renewable sources for electricity - 2013.png.

${ }^{36}$ Greenpeace (2014): El impacto de las energías renovables en la economía con el horizonte de 2030, en http://www.greenpeace.org/espana/Global/espana/2014/Report/cambio-

climatico/Informe $\% 20 \mathrm{ER} \% 20 \mathrm{Economi} \% \mathrm{CC} \% 81 \mathrm{a}$.pdf. Se aborda un estudio comparativo del marco normativo reciente de las energías renovables en España.

${ }^{37}$ Leal-Arcas, Rafael y Alemany Ríos, Juan: "The creation of a European Energy Union", Queen Mary University of London, School of Law Legal Studies, Research Paper, № 206 (2015), pp. 33-37, en http://papers.ssrn.com/sol3/papers.cfm?abstract id=2618232. También serán comentados más adelante.

${ }^{38}$ Million of BTU, British Thermal Unit.

${ }^{39}$ De acuerdo con los datos de la US Energy Information Administration (EIA), en: Natural Gas Weekly Update: http://www.eia.gov/naturalgas/weekly.

${ }^{40}$ Aoun, Marie-Claire: "European energy security challenges and global energy trends: old wine in new bottles?, IstitutoAffari Internazionali, (January 2015), p. 3, en http://www.iai.it/sites/default/files/iaiwp1503.pdf.

${ }^{41}$ Medina, A.: "Así funcionará el mercado de CO2", Expansión.com, 17 de diciembre de 2012, en http://www.expansion.com/2012/12/13/empresas/1355428033.html.
} 
consideraciones económicas y financieras, pero no medioambientales a largo plazo. De acuerdo con Eurostat, la principal aportación para la generación de electricidad en la UE, en el año 2013, vino de la mano de las energías renovables, con un share del 27,3\%, seguido de la energía nuclear y el carbón, con un $26,9 \%$ y un $26,7 \%$, respectivamente; mientras que el gas se situó en un $16,6 \%{ }^{42}$ (véase Figura 1).

Figura 1

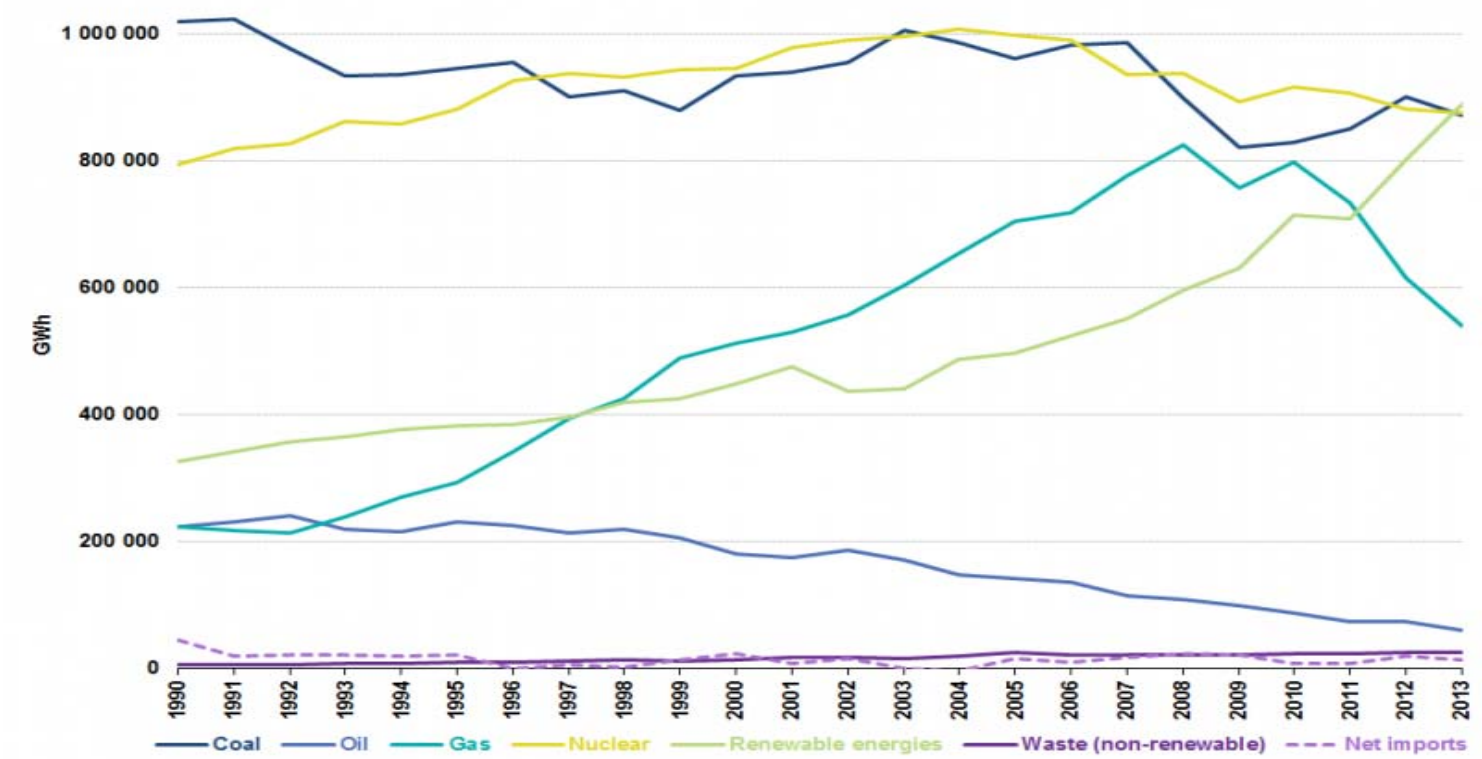

Fuente: Eurostat, 2015: Gross Electricity Generation by fuel EU-28, 1990-2013.

Las señales negativas en los precios conducen a la tercera paradoja, que consiste en destinar los limitados recursos de la Unión a inversiones en infraestructuras gasísticas a corto plazo, en detrimento de las interconexiones eléctricas, imprescindibles en el futuro de una Unión limpia, en un contexto, volvemos a insistir, de contracción de la demanda del gas. Y, es que, en la medida que la persistente tendencia a la baja en el consumo de gas natural en la UE viene a desincentivar la atracción de las inversiones necesarias en infraestructuras gasísticas, cifradas en 100 mil millones de euros ${ }^{43}$, según las estimaciones de la Comisión, estas infraestructuras de interconexión se siguen considerando esenciales para garantizar la diversificación y la seguridad en el suministro de la UE, vía gasoductos, de donde provienen, según vimos, el $86 \%$ de los aprovisionamientos de gas que fluyen a la UE, procedentes, principalmente, de Rusia, Noruega y, en menor medida de Argelia, junto a GNL procedente de Qatar, Argelia y Nigeria, como principales suministradores ${ }^{44}$ (véase Figura 2).

\footnotetext{
${ }^{42}$ Eurostat: Electricity and heat statistics, 2015, en http:// ec.europa.eu/eurostat/statistics-explained/index.php/Electricity and heat statistics.

${ }^{43}$ Comisión, Estrategia Seguridad Energética 2014, op., cit., p.11. La Comisión estima que son necesarios 200 mil millones de euros hasta 2020, aunque se admite que el mercado sólo puede aportar actualmente la mitad de esta cifra.

${ }^{44}$ Comisión, Pocketbook 2014, op., cit., p. 27.
} 
Figura 2

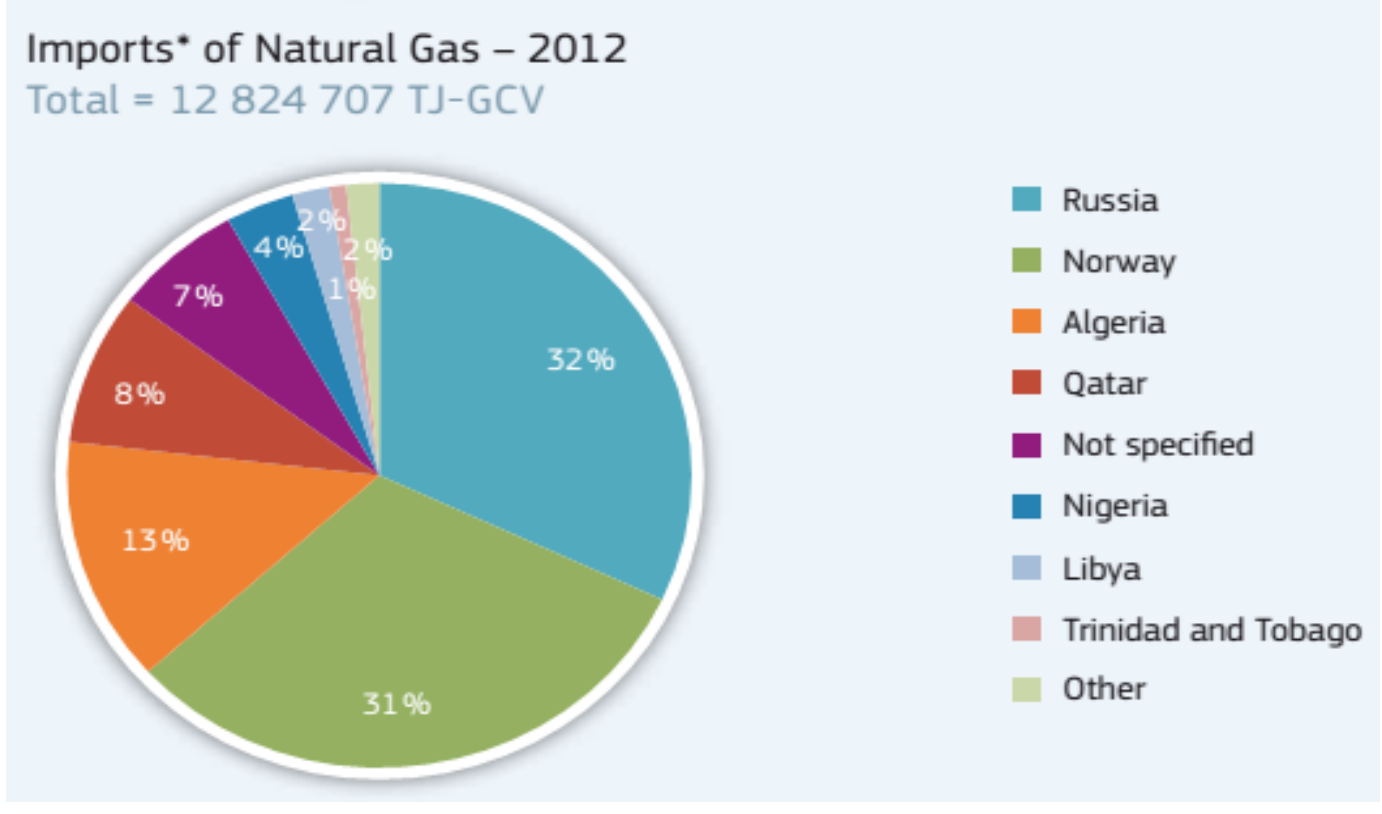

Fuente: Statistical Pocketbook 2014.

Así, en un contexto de contracción de la demanda de gas en la UE y con las respectivas desestimaciones de los proyectos Nabucco y South Stream, que respondían a la recurrente aspiración de transportar el gas procedente del Caspio hacia los mercados europeos con el fin de garantizar la diversificación en el origen de las importaciones y reducir la dependencia de Rusia, parece que la opción más viable, -atendiendo a los márgenes de financiación y con el fin de responder a los intereses de seguridad en el suministro de la Unión en el corto plazo, en un contexto de deterioro de las relaciones con Rusia como consecuencia de la crisis de Ucrania, la anexión de Crimea y el conflicto civil en el Este de Ucrania-, pasa por la extensión del South Caspian Pipeline ${ }^{45}$ para conectar con Turquía, como respuesta más inmediata y menos costosa, dentro de un macroproyecto más amplio como el Corredor Sur del Gas, que da prioridad al Mediterráneo Oriental. El empuje sostenido de la demanda turca, así como de los países balcánicos, representa, sin duda, un notable estímulo para atraer las inversiones necesarias a corto plazo, compensando, de este modo, el hándicap que supone el descenso en el consumo del gas en la UE-28, en una doble dirección: garantizar la rentabilidad de los proyectos y progresar, mínimamente, en la reducción de la dependencia energética de Rusia, en un contexto de creciente tensión geopolítica.

Esta estrategia cortoplacista contradice, sin embargo, los propios compromisos de la Unión en su lucha contra el cambio climático y sus objetivos a largo plazo respecto de la promoción de las renovables, el incremento de la eficiencia energética y la reducción de las emisiones de gases de efecto invernadero (GEI). Y, es que, en la Europa de la energía verde, en un escenario de futuro en el horizonte de 2050, resulta previsible que la seguridad energética de la Unión, de acuerdo con sus propias directrices que comentaremos más adelante, dependa más de las interconexiones de redes eléctricas inteligentes que de las importaciones de hidrocarburos, vía gasoducto; aspecto, por otra parte, reconocido en la propia Estrategia de 2014, cuando afirma que la integración de la energía renovable a gran

\footnotetext{
${ }^{45}$ Para ampliar la información sobre esta extensión consultar: http://www.bp.com/en_az/caspian/operationsprojects/pipelines/SCP.html.
} 
escala requerirá redes eléctricas más inteligentes y nuevas soluciones de almacenamiento de energía ${ }^{46}$.

Sin embargo, observando con cierto detenimiento la selección de proyectos de infraestructura, especificados en el Anexo 2 de la Estrategia de $2014^{47}$, cuando menos, llama la atención que de los 33 proyectos, situados en el Báltico, Europa Oriental y Suroccidental, con un coste estimado de 17 mil millones de euros para una fecha límite fijada en el horizonte de $2020^{48}$, sólo 6 son de electricidad y 27 de gas, de los cuales, sólo 5 corresponden a terminales de GNL; a su vez, del total de los 33, sólo 2 se ubican en Europa Suroccidental, más concretamente, en España: el gasoducto Midcat, que contribuiría a la diversificación en el origen de las importaciones para evacuar hacia Europa el gas procedente de Argelia, a través del Medgaz; y el cable submarino de Alta tensión (HVDC), entre Aquitania y el País Vasco, para la favorecer la interconexión entre España y Francia. Ambos proyectos, por cierto, pendientes de confirmación.

Un simple análisis de estas cifras pone de manifiesto la incapacidad de la Comisión de establecer los equilibrios mínimos necesarios, entre su vecindad este y sur, entre las exigencias del corto plazo y la planificación a medio/largo plazo que requieren los desafíos del cambio climático, sacrificando los escenarios de futuro, construidos sobre la base de una transición viable hacia un modelo de descarbonización, compatible con la seguridad y la competitividad económica, en favor de las urgencias derivadas de un pragmatismo político cortoplacista, inspirado por la crisis con Rusia, a la que nos unen, por cierto, unas sólidas relaciones de interdependencia energética, a largo plazo ${ }^{49}$.

Y, es que, aparte del Corredor Sur del Gas, que da prioridad a la vecindad oriental, no se vislumbran, por el momento, demasiados proyectos energéticos para los próximos cinco años $^{50}$ para incrementar la seguridad energética de la Unión. A pesar de que la opción del GNL también contribuye a la estrategia de diversificación, las condiciones de su mercado, ya comentadas, hacen que la UE deba competir con otras regiones como Asia, que ya concentra el $54 \%$ de la capacidad de regasificación global $^{51}$, y donde se muestran dispuestos a pagar los precios más altos.

Por tanto, dadas las condiciones actuales, -comerciales, económicas, financieras y geopolíticas- resulta previsible que la estrategia de diversificación de los suministros de gas en el corto y el medio plazo se base en la optimización de las infraestructuras existentes, gasoductos y terminales de GNL, tratando de aliviar la situación de islas energéticas de las regiones del Báltico y la Península Ibérica, donde España podría desempeñar un importante papel como país de tránsito entre las fuentes de suministro procedentes de África y los mercados europeos, de acuerdo con la estrategia de diversificación de la UE para reducir la

\footnotetext{
${ }^{46}$ Comsión: Estrategia Seguridad Energética 2014, op., cit., p.15. Estos objetivos de electrificación también son reclamados en otros documentos estratégicos de la Comisión como A framework strategy for a resilient Energy Union with s Foward-Looking Climate Change Policy, COM(2015), 80 final, de 25 de febrero de 2015, donde, para impulsar la interconexión eléctrica en la UE, se insiste en la urgencia de alcanzar al menos el $10 \%$ de la capacidad de producción eléctrica instalada para 2020.

${ }^{47}$ Comisión: Estrategia Seguridad Energética 2014, op., cit., pp. 26 y ss. (Anexo 2).

${ }^{48}$ Ibid., p. 12.

${ }^{49}$ Andoura y Vinois: From de European Energy Community, op., cit., pp. 93-99, donde los autores consideran que las relaciones entre la UE y Rusia deben repararse, dada la situación de sólida interdependencia energética a largo plazo. Se recomienda la consulta de las gráficas y tablas que reflejan la dependencia energética de Rusia por Estado Miembro de la UE; el destino de las exportaciones de hidrocarburos, así como los sectores donde opera Gazprom en los distintos países europeos (UE y Balcanes), donde destacan, Reino Unido, Serbia y Holanda.

${ }^{50}$ Aoun, Marie-Clarie: European Energy Security, op., cit., p.12.

${ }^{51}$ Ibid.
} 
dependencia energética de Rusia y, según consta, en la Estrategia de Seguridad Energética Nacional, aprobada por el Consejo de Seguridad Nacional de España, el pasado 20 de julio de $2015^{52}$. En este sentido, resulta importante acometer sin más demora la infraestructura de interconexión correspondiente al corredor Norte-Sur Occidental (NSI West Gas) ${ }^{53}$, que permitiría incrementar la capacidad de suministro con las aportaciones de gas argelino y las plantas de regasificación atlánticas y mediterráneas.

\subsection{Constantes en la estrategia de seguridad energética europea en un entorno de transformación global}

El dinamismo del panorama energético global descrito pivota, sin embargo, en torno a cuatro anclajes, sobre los que se articula la estrategia de seguridad energética de una UE a 28. Este choque de tendencias, transformación vs. inmovilismo, representa una fuerza motriz sobre la que se configura un escenario surcado de contradicciones y paradojas que, sin duda, contribuyen a limitar la capacidad de actuación y proyección de poder, tanto de la UE como de sus EM, en las dimensiones interna e internacional.

En este sentido, la primera constante a considerar, en un panorama energético de transformación global, es la recurrente situación de dependencia de la UE-28, derivada de un consumo energético ineficiente, a la vez que su limitada capacidad de producción de energía autóctona $^{54}$, lo que obliga a la Unión a nutrirse de las fuentes de energía, fósiles y renovables, que proporciona su espacio de vecindad, en permanente tensión geopolítica, entre otras causas, como consecuencia del persistente y cuestionable empeño de la UE-28 en disputar a Rusia su área de influencia en el desarrollo de la estrategia de diversificación europea. En segundo lugar, los imperativos del cambio climático que, a medio y largo plazo, exigirán la construcción de un modelo sostenible e inteligente, fundamentado en la integración y uso de nuevas y renovables fuentes de energía, que garanticen el camino irreversible hacia la descarbonización y que, sin duda, contribuirán a reducir la dependencia fósil de Rusia. En tercer lugar, la naturaleza híbrida y singular de la UE, donde conviven 28 políticas nacionales, que responden a dispares realidades energéticas, junto a la política energética comunitaria, caracterizada por cierta eficacia normativa, pero con importantes limitaciones geopolíticas. Por último, y en cuarto lugar, la pérdida progresiva de influencia de la UE en los mercados internacionales de la energía como consecuencia del desplazamiento del peso de la demanda hacia los países emergentes, especialmente, asiáticos; una realidad, que, en general, no responde más que el reflejo de la pérdida de influencia y poder de la UE en el actual escenario de la globalización. Cuestión, por otra parte, admitida, de forma inequívoca, por el nuevo Presidente de la Comisión, Jean Claude Juncker, en julio del pasado año, en la presentación sus directrices políticas, cuando afirmaba:

After spending several years concentrating on crisis management, Europe is finding it is often ill-prepared for the global challenges ahead, be it with regard to the digital age, the race for innovation and skills, the scarcity of natural resources, the safety of our food, the cost of

\footnotetext{
${ }^{52}$ Estrategia de Seguridad Energética Nacional, en: http://www.lamoncloa.gob.es/serviciosdeprensa/notasprensa/Documents/ESTRATEGIA\%20DE\%20SEGURID AD\%20ENERG\%C3\%89TICA\%20NACIONAL\%20(WEB).pdf.

${ }^{53}$ Escribano, Gonzalo: "Revisión del mapa energético europeo", Real Instituto Elcano, 14 de marzo de 2014, en: http://www.realinstitutoelcano.org/wps/portal/rielcano/contenido?WCM_GLOBAL_CONTEXT=/elcano/elcano es/programas/energiacambioclimatico/publicaciones/escribano-revision-mapa-energetico-europeo.

${ }^{54}$ Eurostat: Energy production and imports, en

http://ec.europa.eu/eurostat/statistics-explained/index.php/Energy production and imports; según la Comisión, la producción de energía primaria de la UE-20, viene experimentando un descenso generalizado desde la pasada década.
} 
energy, the impact of climate change, the ageing of our population or the pain and poverty at Europe's external borders ${ }^{55}$.

Sobre la base de estos imponderables y frente a los desafíos de un panorama energético global en constante proceso de cambio, la UE ha ido tejiendo un complejo entramado político y normativo, definido por encrucijadas: a medio camino entre las necesidades de adaptación a los desafíos del corto y medio plazo y las proyecciones de futuro, basadas en un modelo económico respetuoso con el medioambiente, conciliador entre el Clima y la Energía; situándose en la intersección entre los intereses energéticos nacionales y los objetivos comunitarios; exportando un acervo comunitario, donde, en realidad, se camuflan intereses geopolíticos de los Estados; maquillando los desajustes entre un exhaustivo desarrollo de la dimensión regulatoria que contrasta con una limitada integración física; en la dialéctica entre los avances y el inmovilismo; en definitiva, a medio camino entre el liderazgo y el progresivo desplazamiento como epicentro de poder global.

\subsection{Tres líneas de acción estratégica}

Así, a partir de 2011, en un contexto de turbulencia internacional, la UE, vía instituciones, ha venido desarrollando un dinámico, complejo y adaptativo proceso de formulación política y normativa, mediante el desarrollo de distintas medidas, iniciativas y proyectos, al servicio de los, ya mencionados, cuatro grandes ejes, que vienen conformando la estrategia de seguridad energética de la UE. Medidas que, a su vez, se organizan en torno a tres líneas de acción estratégica, a saber: 1) desarrollo del mercado interior de la energía; 2) estrategia de transición hacia la descarbonización y eficiencia energéticas; y, 3) medidas de política energética exterior. Líneas que, precisamente, conforman los tres pilares de la Energy Union, iniciativa estrella de la Comisión Juncker, puesta en marcha en febrero del presente $2015^{56}$.

\subsubsection{Mercado interior}

En lo que se refiere al mercado interior de la energía como primera línea de acción, desde 2011 a la actualidad, la Comisión se ha mostrado especialmente activa en el fomento, desarrollo y financiación de las redes transeuropeas de interconexión con el fin de conectar los mercados energéticos que permanecen aislados, contribuir a la diversificación en el origen, integrar las aportaciones de las renovables, a la vez que reforzar los mecanismos de solidaridad entre los EM.

A este respecto, cabe destacar, sin ánimo de ser exhaustivos, iniciativas como el denominado Energy Infraestructure Package, de octubre de 2011, adoptado para identificar los corredores energéticos prioritarios para transportar petróleo, gas y electricidad; el Reglamento 347/2013, del 17 de abril de 2013, donde se especifican las denominadas Guidelines for transeuropean energy infraestructure. De acuerdo con este Reglamento, el 14 de octubre de 2013, la Comisión designaba una lista de 248 proyectos de infraestructura estratégica, denominados Projects of Common Interests (PCIs) ${ }^{57}$, en transmisiones de gas y electricidad, almacenamiento y terminales GNL. Estos proyectos podrían beneficiarse del

\footnotetext{
${ }^{55}$ Juncker, Jean-Claude: "A new start for Europe: my agenda for jobs, growth, fairness and democratic change", Political Guidelines for the next European Commission, Estrasburgo, 15 de Julio de 2014

${ }^{56}$ Cuatro años después de que la idea de una Unión Energética fuese presentada por primera vez por el entonces Presidente del Parlamento Europeo, Jerzy Buzek y el anterior Presidente de la Comisión, Jacques Delors, en mayo de 2014, el actual Presidente de la Comisión Europea, Jean-Claude Juncker, prometía materializar la idea de una Unión Energética y convertirla en una de sus prioridades de su mandato. Se recomienda consultar: LealArcas y Alemany: The creation of a European Energy Union, op., cit.,

57 Projects of Common Interests, en: https://ec.europa.eu/energy/en/topics/infrastructure/projects-commoninterest.
} 
acceso a una vía de financiación cifrada en más de cinco mil millones de euros para el período 2014-2020, procedentes del nuevo mecanismo Connecting Europe Facility (CEF) ${ }^{58}$, adoptado mediante el Reglamento 1316/2013, de 11 de diciembre de 2013.

De hecho, uno de los primeros resultados tangibles de este proyecto ha sido la materialización de la interconexión eléctrica entre España y Francia, a través de la línea de alta tensión entre Santa Llogaia y Baixàs ${ }^{59}$; sin embargo, esta iniciativa representa una excepción, ya que, analizando con cierto detenimiento las propuestas de financiación y los proyectos seleccionados, el destino de los fondos CEF, para los años 2014 y 2015, se dirigen de forma prioritaria a las regiones de Europa Central, Europa Suroriental y el Báltico ${ }^{60}$ (véase Figura 3).

Figura 3

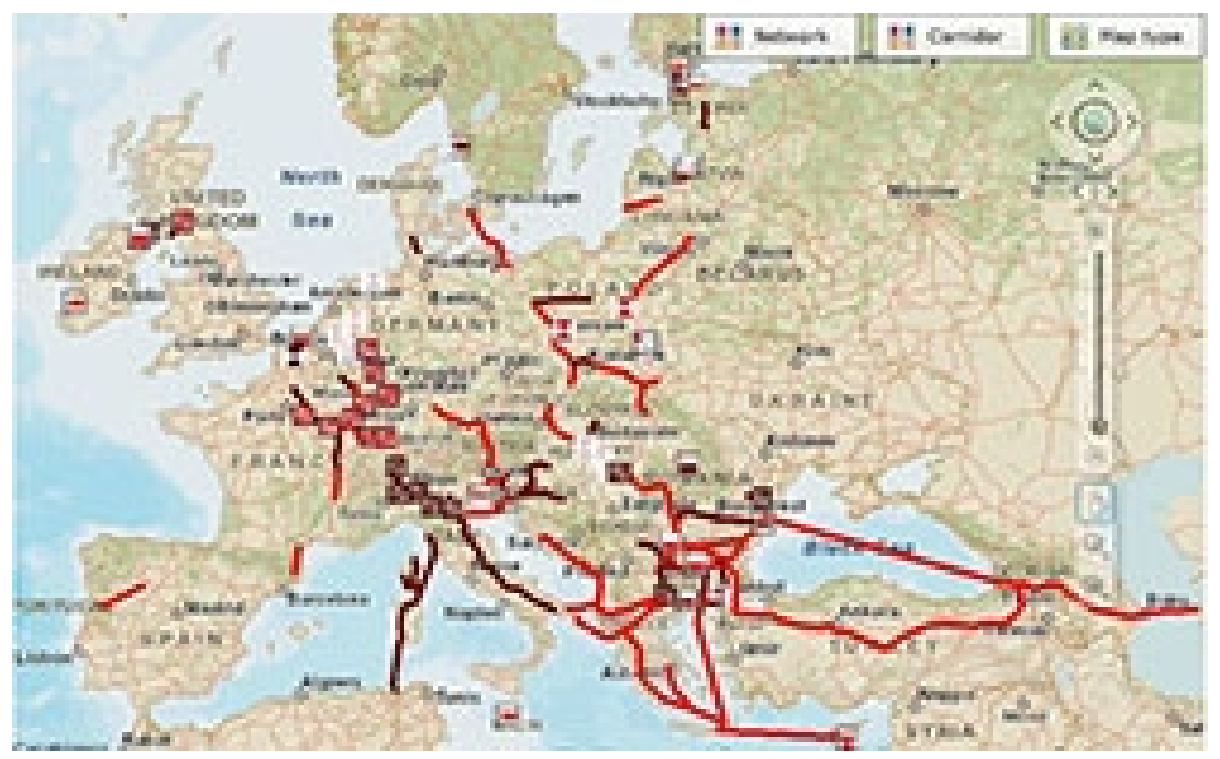

Fuente: EU Projects of Common Interests.

\footnotetext{
${ }^{58}$ Reglamento 1316/2013, de 11 de diciembre de 2013, por el que se establece el Connecting Europe Facility, en: http://ec.europa.eu/digital-agenda/en/connecting-europe-facility; Leal y Alemany advierten de que este instrumento de financiación ha sido muy criticado por las organizaciones ecologistas, que señalan el mal gasto de miles de millones de euros en infraestructuras gasísticas innecesarias, dada el descenso en la demanda.

${ }^{59}$ En lo que respecta a las interconexiones eléctricas, el 20 de febrero de 2015, el Presidente del Gobierno, Mariano Rajoy, y el Primer Ministro francés, Manuel Valls, inauguraban la interconexión eléctrica que conecta Santa Llogaia, en Girona, y Baixàs, en Francia. Se trata de la interconexión con línea eléctrica soterrada más larga del mundo, 64,5 kilómetros, que permitirá duplicar la interconexión entre España y Francia, pasando de un 3 a un $6 \%$, esto es, de 1.400 a 2.800 Megawation (MW). Este incremento queda lejos de los objetivos recomendados por la Comisión, que establece un mínimo de interconexión de $10 \%$ de capacidad instalada: 10.000 MW, de acuerdo con la Comunicación de la Comisión, relativa a la consecución de Objetivo de Interconexión del 10\%, COM (2015) 82, de 25 de febrero de 2015. Asimismo, y al servicio de esta estrategia, el 4 de marzo de 2015, se presentaba la Declaración de Madrid, en el marco de la Cumbre para las Interconexiones energéticas España-Francia-Portugal-Comisión Europea-BEI, donde se daba a conocer el Documento de estrategia común para el desarrollo de la interconexión de la Península Ibérica con el mercado interior de la electricidad y fuera de él, donde se fija el objetivo de elevar la capacidad de intercambio eléctrico entre España y Francia hasta los $8.000 \mathrm{MW}$ para 2020.

${ }^{60}$ Projects of Common Interest, op., cit., en http://ec.europa.eu/energy/en/topics/infrastructure/projects-common-interest; https://ec.europa.eu/energy/sites/ener/files/documents/20141121_cef_energy lists.pdf.
} 
Retomando el repaso cronológico, en 2014, la Comisión presentará dos Comunicaciones importantes, que merecen ser comentadas: COM (2014) 634 final, del 13 de octubre, titulada: Progress towards completing internal energy market, donde se admite, como opción intermedia, una aproximación gradual de los distintos espacios regionales, en respuesta a realidades energéticas muy diferentes ${ }^{61}$, con el fin de progresar hacia la máxima aspiración del largo plazo, fijada en la Europeización definitiva del mercado energético interior. En la Comunicación, la Comisión se posiciona en un bottom-up approach para afirmar que:

a regional approach has been and will also in the future be decisive for the integration of the European Energy market. It allows for immediate results and can stimulate cross-border exchanges, increase security of supply and facilitate the integration of renewables. Often cooperation in smaller group than the entire EU can go faster and can be better suited to address the particular challenges of the region concerned ${ }^{62}$

Por otra parte, la COM (2014) 903 final, de 26 de noviembre, supone la puesta en marcha de otra de las grandes iniciativas de la Comisión Juncker: el denominado Investment Plan for Europe $^{63}$ (Plan Juncker), con el que se pretende movilizar 315 mil millones de euros en inversiones privadas y públicas a lo largo de tres años con los objetivos de impulsar las inversiones estratégicas, aumentar la competitividad y fomentar el crecimiento económico a largo plazo de la UE. En lo que se refiere a las Inversiones estratégicas (energía, infraestructuras, innovación, educación), se contempla la creación de un Fondo Europeo para las Inversiones Estratégicas que, inicialmente, utilizará financiación pública para movilizar inversión privada adicional. El Fondo estará constituido sobre la base de una garantía de 21 mil millones de euros (16 mil millones, procedentes del presupuesto de la UE y 5 mil millones, procedentes del Banco Europeo de Inversiones) con los que se pretende generar un efecto multiplicador en inversión privada adicional que supere los 300 mil millones de euros. La clave se encuentra en el procedimiento para seleccionar los proyectos, teniendo en cuenta que países como Alemania, Francia, Italia y España ya han aportado dinero y que los Fondos buscan la rentabilidad, no corregir desequilibrios regionales, por lo que es previsible que las inversiones se concentren en las regiones prioritarias, que garanticen posibilidad de retorno. Y como vamos comprobando, la región Suroccidental del Europa no se vislumbra en el horizonte de prioridades en el corto/medio plazo.

\subsubsection{Descarbonización}

En cuanto a la segunda línea de acción, sobre Clima y Energía, la Comisión ha ido trazando cuidadosamente el camino de la transición hacia un modelo eficiente y descarbonizado, especialmente desde el año 2007, con la puesta en marcha de su política de "las tres 20s"; el Paquete Clima y Energía, de 2009; y Energía 2020, de 2010. Es a partir de 2011, precisamente en el contexto de las profundas convulsiones internacionales ya comentadas, cuando en el seno de la UE se vislumbran grandes expectativas y se fijan objetivos cuasi visionarios en la lucha contra el cambio climático con el fin de emprender una revolución industrial, basada en tecnología de vanguardia limpia e inteligente, que impulse la ansiada

\footnotetext{
${ }^{61}$ En lo que se refiere a la electricidad, existen mercados diferenciados como Nord Pool, Pentalateral Energy Forum y el mercado Ibérico de la electricidad; en cuanto a la seguridad en el suministro del gas, la situación de dependencia es mucho mayor para los países de Europa Central y Oriental. Ver: Palle, A.: "Regional Dimension to Europe's energy integration", The Oxford Institute for Energy Studies, (2013), citado en Leal y Alemay, "The creation of...", op., cit., p. 20.

${ }^{62}$ COM (2014) 634 final, 13 de octubre de 2014, p. 9.

${ }^{63}$ Investment Plan for Europe, en http://ec.europa.eu/priorities/jobs-growth-investment/plan/index en.htm.
} 
recuperación económica y facilite la conversión hacia un modelo energético más sostenible ${ }^{64}$, metas y expectativas, por otra parte, atemperadas, como veremos, a finales de 2014.

En este sentido, el firme compromiso de la Comisión en la lucha contra el cambio climático y los objetivos de transición hacia la descarbonización no dejan lugar a dudas en los sucesivos documentos emitidos por la institución: COM (2011)0031 final, de 31 de enero de 2011, Renewable energy: progressing towards 2020 target; Horizon 2020: the new EU framework programme for research and innovation, de Junio de 2011; COM (2011) 885 final, de 15 de diciembre de 2011, Roadmap for moving to a low-carbon economy in 2050; Directiva 2012/27/EU, de 25 de octubre de 2012, On energy efficiency; COM (2013) 169 final, de 27 de marzo de 2013, Green Paper: A 2030 framework for climate and energy policies; COM (2014) 15 final, de 22 de enero de 2014, A policy framework for climate and energy in the period from 2020-2030; COM (2014) 520 final, de 23 de julio de 2014, Energy efficiency and its contribution to energy security on the 2030 framework for climate and energy policy: Energy and Climate Package for 2030; European Council, Conclussions on 2030 climate and energy policy framework, de octubre de 2014; COM (2015) 80 final, de 25 de febrero de 2015, Framework for a Resilient Energy Union with a foward-looking climate change policy.

Sin embargo, a pesar de las grandes expectativas iniciales, el último Paquete de Energía y Clima para $2030^{65}$, aceptado en las Conclusiones del Consejo Europeo, de 23 y 24 octubre de 2014, de acuerdo con las orientaciones previas de la Comisión en sus respectivas Comunicaciones de enero y julio de 2014, supone un acuerdo de mínimos para seguir en la senda hacia una economía descarbonizada, y salvar la posición de la UE en la Conferencia sobre el Clima, prevista para diciembre de 2015 en París ${ }^{66}$. Y es que, los objetivos presentados son, cuando menos, muy limitados: en el caso de las renovables, se ha pasado de un $20 \%$ en 2020 , a un $27 \%$ para 2030 , vinculante para el conjunto de la UE, pero no vinculante por países; en cuanto a la reducción de emisiones GEI, se plantea un recorte del $40 \%$ para 2030, con respecto a las emisiones registradas en 1990 , como objetivo vinculante por países; en el ámbito de la eficiencia, el Paquete marca como referencia un objetivo, meramente indicativo, en torno al 27\%, aunque sin acompañamiento de planes de acción ni objetivos nacionales vinculantes, y sin ninguna exigencia de criterios para sectores prioritarios como el transporte y la construcción ${ }^{67}$.

Es el ámbito de la eficiencia el que se ha visto especialmente perjudicado, ya que, porcentajes más elevados y vinculantes implicarían reforzar la seguridad energética mediante el control por el lado de la demanda, cuando, en una situación de limitado crecimiento y descenso en el consumo energético, lo que se pretende es incrementar esa demanda para atraer y rentabilizar las inversiones necesarias. Este ambiguo y titubeante modelo de aproximación

\footnotetext{
${ }^{64}$ Andoura y Vinois, From the European Energy...", op. cit., p. 26.

${ }^{65}$ COM (2015) 80 final: A framework strategy for a resilient Energy Union with a foward-looking climate change policy, 25 de febrero de 2015.

${ }^{66}$ Precisamente, y de cara a la próxima Cumbre del Clima a celebrar en París, el pasado 26 de mayo, la Asamblea Nacional francesa aprobaba la denominada Ley de Transición Energética con el fin de transformar el modelo energético francés, sostenido en la energía nuclear, promoviendo la opción de las renovables, el transporte limpio y una edificación sostenible y eficiente. Los objetivos se centran en la reducción de un $40 \%$ de las emisiones GEI, en sintonía con la UE, una aportación del $32 \%$ de energías renovables para cubrir el consumo energético a finales de 2030, además de una reducción de la aportación de la energía nuclear para la producción de electricidad, que no deberá superar el 50\% en el horizonte de 2025. Asimismo, el pasado 4 de agosto, el Presidente Obama presentaba su Plan de Energía Limpia, centrado en la reducción de las emisiones de carbono en un 32\% para 2030, respecto de los niveles de 2005, así como la transformación radical del sector eléctrico mediante la promoción de las energías renovables en detrimento del carbón.

${ }^{67}$ Leal y Alemany, "The creation of...", op., cit., p. 31.
} 
al desafío que supone la eficiencia energética con un, más que modesto incremento al $27 \%$, aunque con el compromiso de revisarlo en 2020 para no pasar, seguramente, de un $30 \%$ no vinculante-, pone en evidencia el enfoque cortoplacista de la Comisión.

El problema es que esta política se dejará sentir en el largo plazo, en la medida que desincentiva la movilización de las inversiones necesarias, públicas y privadas, en el corto plazo, especialmente, en el sector de la construcción, que absorbe el $40 \%$ del consumo de la energía en la UE ${ }^{68}$. En realidad, el Paquete Clima y Energía para 2030 representa, de nuevo, una estrategia a medio camino entre una política cré́ble hacia la descarbonización y el compromiso con la competitividad industrial en un contexto de frágil crecimiento económico. Así, será difícil alcanzar los objetivos de $80 \%-95 \%$ en la reducción de los gases GEI, ya comprometidos en la Hoja de Ruta para 2050, presentada tan sólo tres años antes y, nuevamente, marcados en el documento de 25 puntos aprobado por el Consejo de Ministros de la UE, el pasado 18 de septiembre ${ }^{69}$, para fijar la posición común que llevarán en diciembre a la Cumbre del Clima de París, donde es previsible que se apruebe el nuevo Protocolo que sustituya al de Kyoto. Por tanto, aunque titubeante, el camino hacia la descarbonización emprendido por la UE resulta irreversible. Este cambio de modelo energético en los escenarios de futuro repercutirá, necesariamente, en las relaciones energéticas mediterráneas, como estudiaremos más adelante.

\subsubsection{Medidas de Política Energética exterior: la cuenca del Mediterráneo ampliado}

En cuanto a la tercera línea de acción, las directrices de la política exterior energética de la UE aparecen sintetizadas en la propia Estrategia Europea de la Seguridad Energética para 2014, donde, bajo el epígrafe de Medidas Clave ${ }^{70}$, se afirma que la Comisión:

- Asegurará la aplicación de las medidas identificadas en su Comunicación sobre la política energética exterior en septiembre de 2011, COM (2011)539 final, de 7 de septiembre de 2011, La política energética de la UE: establecer asociaciones más allá de nuestra fronteras

- Revisará la Decisión $n^{\circ}$ 994/2012/UE, por la que se establece un mecanismo de intercambio de información con respecto a los acuerdos intergubernamentales entre los EMy terceros países en el sector de la energía.

- Evaluará las opciones de mecanismos de agrupación voluntaria de la demanda que puedan aumentar el poder negociador de los compradores europeos con arreglo a la legislación de la UE y el Derecho mercantil

- Promoverá con el Servicio Europeo de Acción Exterior un uso más sistémico de las herramientas de política exterior para promover objetivos de la política energética exterior y reforzar la coherencia entre los objetivos energéticos y los de política exterior.

\footnotetext{
${ }^{68}$ Ibid.

${ }^{69}$ Council of the European Union: Preparation for the 21th session of the Conference of the Parties to the United Nations Framework Convention on Climate Change and the 11th sesion of the Meeting of the Parties to de Kyoto Protocol, Paris 2015, 18/09/2015, en

http://www.consilium.europa.eu/en/press/press-releases/2015/09/18-counclusions-un-climate-changeconference-paris-2015/; además del compromiso para que las emisiones europeas se vean reducidas entre un $80 \%$ y $95 \%$ para 2050 , el documento insta a que las emisiones de gases de efecto invernadero se reduzcan en todo el planeta al menos un $50 \%$ en 2050 , respecto a las de 1990 . Se trata de iniciativas en línea con el objetivo planteado por el panel de expertos de la ONU para intentar evitar que la temperatura a final de siglo suba más de $2^{\circ} \mathrm{C}$.

${ }^{70}$ Comisión, Estrategia de seguridad energética 2014, op., cit., p. 22.
} 
Las dos primeras medidas merecen ser comentadas. En lo que se refiere a la Comunicación sobre La política energética de la $U E$, se trata de la respuesta al mandato del Consejo Europeo, de 4 de febrero de 2011, donde se solicita a la Comisión el desarrollo de un paquete de medidas de política exterior destinadas al fortalecimiento del mercado interior de la energía para 2014. La propuesta de la Comisión a este requerimiento se centrará en la seguridad en el suministro y la cooperación internacional, pero desde un enfoque novedoso, en la medida que la política energética exterior se pondrá al servicio de la consecución del mercado interior de la energía, y no a la inversa, como venía siendo habitual, esto es, un mercado interior fortalecido, que garantizase la proyección exterior de la UE ${ }^{71}$. De esta forma, sobre la base de una estrategia de europeización externa, se propondrá la incorporación de los mercados energéticos de la vecindad europea ${ }^{72}$, a través de diversos mecanismos de cooperación transfronteriza y a partir de una aproximación diferenciada, tomando como referencia la Carta de la Energía y la exportación del acervo comunitario.

La Comisión identifica dos áreas de vecindad, a las que imprime un tratamiento diferenciado. El Corredor Sur del Gas, como infraestructura estratégica prioritaria en la ruta de suministro procedente del Caspio y Oriente Medio; y la región del Mediterráneo, a la que reconoce su importancia en el abastecimiento de suministros energéticos hacia la UE, en combustibles fósiles y, potencialmente, en la electricidad generada por energías renovables ${ }^{73}$. Precisamente, para fomentar el desarrollo de las renovables, se propone la puesta en marcha de una Asociación Energética entre la UE y los países del Sur del Mediterráneo ${ }^{74}$ con el fin de emprender una reforma urgente del mercado energético para estimular las inversiones necesarias en energía limpia y eficiente, dada la parálisis del Plan Solar del Mediterráneo, incapaz de movilizar recursos, promover un calendario viable y avanzar en el despliegue de las infraestructuras energéticas renovables en la región. Por su parte, y en lo que se refiere a los combustibles fósiles, la Comunicación destaca el papel de Argelia y Libia (entre otros productores), como suministradores alternativos para reducir la dependencia de Rusia.

De acuerdo con la Comisión, basándose en experiencias pasadas, las relaciones bilaterales energéticas entre los EM y países suministradores o de tránsito han resultado en la fragmentación del mercado interno, más que en su fortalecimiento, por lo que se propone la adopción de una Decisión que establezca un mecanismo de intercambio de información, en lo que se refiere a los acuerdos intergubernamentales entre los EM y terceros en el sector de la energía $^{75}$. El 25 de octubre de 2012, sobre la base de esta propuesta, se adoptará la Decisión 994/2012, con el fin de aportar un mayor grado de transparencia en las relaciones energéticas de una UE-28, al servicio de un ejercicio de coherencia en la política energética exterior desplegada por la Unión.

La aplicación de este Mecanismo se enfrenta, sin embargo, a las resistencias de los EM, que no se muestran dispuestos a renunciar a sus prerrogativas en un ámbito tan sensible como el de la energía. Por este motivo, en su Estrategia de 2014, la Comisión vuelve a insistir sobre la importancia crucial de informar con celeridad a la Comisión antes de concluir acuerdos

\footnotetext{
${ }^{71}$ Escribano, Gonzalo y Steinberg, Federico: "La europeización de la política de seguridad energética y sus implicaciones para España", Revista Economía Industrial, No 384 (Junio 2012) p. 26, en http://www.minetur.gob.es/Publicaciones/Publicacionesperiodicas/EconomiaIndustrial/RevistaEconomiaIndustri al/384/Gonzalo\%20Escribano.pdf.

${ }^{72}$ Ibid., p. 27.

${ }^{73}$ COM (2011) 539 final, p. 5.

${ }^{74}$ Ibid., p. 7. Esta propuesta de Asociación Energética se encuentra en la línea de la Asociación para la democracia y la prosperidad con los países del Mediterráneo Meridional: COM (2011) 200 final, de 8 de marzo de 2011, con la que se pretendía a apoyar a los países de la región, comprometidos con reformas en favor de la democracia, en plena efervescencia de la Primavera Árabe.

${ }^{75}$ COM (2011) 539 final p. 4.
} 
intergubernamentales que puedan afectar la seguridad en el suministro y las opciones de diversificación del conjunto de la Unión, por lo que se estima que EM y empresas relevantes deberán solicitar el asesoramiento de la Comisión durante las negociaciones, dejando la puerta abierta a una revisión de la Decisión 994/2012/UE ${ }^{76}$.

Continuando en 2012, en el marco de las profundas y traumáticas convulsiones en los países de la ribera sur del Mediterráneo, la UE se propone la búsqueda y articulación de nuevos instrumentos, mecanismos e iniciativas que promuevan, en diferentes ámbitos, una cooperación más estrecha entre los países del Magreb, al servicio de dos ejes estratégicos: el fortalecimiento de la integración regional; y la consolidación de los procesos de democratización y modernización, tal como queda reflejado en la Joint Communication Supporting closer cooperation and regional integration in the Maghreb: Algeria, Libya, Mauritania, Morocco and Tunisia ${ }^{77}$.

En lo que se refiere al campo de la energía, además de los conocidos y recurrentes planteamientos sobre la importancia de los proyectos sobre energías renovables, eficiencia energética o mercado integrado de la electricidad y sus potenciales beneficios para las relaciones de cooperación entre las dos orillas, la única iniciativa interesante se configura en torno a la propuesta de desarrollo de la denominada West-Mediterranean electriciy area 2020-2025 $5^{78}$, que discurriría sobre dos corredores energéticos: el primero, entre Argelia, Marruecos, España y Francia; y el segundo, entre Argelia, Libia, Túnez e Italia. Para ello, se propone el establecimiento de una serie de pasos concretos $^{79}$, que, sin embargo, no van más allá de dejar constancia de la preocupación ante la falta de un entorno de seguridad jurídica apropiado y de la necesidad de establecer marcos regulatorios y comerciales adecuados para la reforma del sector en favor de la integración de los mercados energéticos.

En respuesta a las directrices formuladas en la anterior JOIN (2012) 36, presentadas por la Alta Representante, la Comisión emitirá, el 27 de septiembre de 2013, un Memorándum, que servirá de documento base para el Primer Diálogo Ministerial UE-Magreb sobre cooperación regional. En este Documento, el capítulo de la energía ni siquiera cuenta con su propio epígrafe en el orden de prioridades de este primer encuentro, quedando rebajado a la categoría de subtema, junto a turismo, comunicación e información, de acuerdo con el punto 3, referido a cuestiones, supuestamente más importantes, como industria, infraestructura, comercio, inversión y tecnología.

Ya en 2014, la dimensión exterior de la política energética de la UE será abordada en la, ya mencionada, Estrategia Europea de Seguridad Energética, concretamente, el punto 7, referido a la diversificación de las fuentes externas de abastecimiento y las infraestructuras correspondientes, donde se destacan los suministros de gas (7.1); y uranio y combustible nuclear (7.2), sin ninguna referencia a las renovables, valoradas en el Estrategia, como aportación de energía autóctona ${ }^{80}$, y no en su dimensión exterior, siquiera, como fuentes

\footnotetext{
${ }^{76}$ Comisión: Estrategia Seguridad Energética, 2014, op. cit., p. 21.

${ }^{77}$ JOIN (2012) 36 final de 17 de diciembre de 2012.

${ }^{78}$ Ibid., p. 13.

${ }^{79}$ Ibid.

${ }^{80}$ De acuerdo con el Punto 5: "Aumentar la producción de energía en la Unión Europea", donde se considera que la Unión puede reducir su dependencia respecto de determinados proveedores y combustibles, maximizando el uso de fuentes propias de energía como las renovables y la energía nuclear, así como la producción de combustibles fósiles competitivos, como el denominado carbón limpio, pp.14-17.
} 
potenciales de suministro procedentes de la ribera sur del Mediterráneo para la generación de electricidad potencialmente exportable hacia los mercados europeos ${ }^{81}$.

En consecuencia, la relevancia del Norte de África en la Estrategia se encuentra relacionada con el gas, $\mathrm{y}$, más concretamente, con recursos potencialmente enormes de hidrocarburos no explorados o explotados y con la ventaja de la proximidad geográfica ${ }^{82}$, donde, por cierto, no se realiza ni el más mínimo esfuerzo por aportar datos específicos sobre las estimaciones de las reservas convencionales y no convencionales en la zona ${ }^{83}$. Como conclusión, y en lo que respecta al Norte de África, la Estrategia aconseja mejorar las interconexiones internas para asegurar que el gas de los proveedores llegue a todos los mercados regionales $^{84}$, sin ningún tipo de medida concreta, plan de acción, previsión presupuestaria o proyección de volumen de flujo. Esta indefinición contrasta con las especificaciones referidas al Corredor del Sur de Gas y los proyectos de interés común $\operatorname{asociados}^{85}$, valorados como infraestructuras críticas para la seguridad en el suministro de la UE.

Quizás, para subsanar estas carencias, complementar la falta de visión estratégica de este Documento "estratégico", y en sintonía con las directrices de la mencionada JOIN (2012) 36, en favor del reforzamiento de la cooperación regional en el Mediterráneo, el 11 de julio de 2014, el entonces Vicepresidente de la Comisión, Günther H. Oettinger, anunciaba la creación de una Plataforma del Gas con el fin de incrementar la seguridad en el suministro y las oportunidades de intercambio comercial para los países del Norte de África y del Este del Mediterráneo, de acuerdo con una concepción de un Mediterráneo ampliado ${ }^{86}$. Los espectaculares descubrimientos de varios yacimientos de petróleo y gas en la denominada Cuenca de Levante, especialmente, los yacimientos de gas Afrodita y Leviatán, en aguas territoriales de Chipre e Israel, respectivamente, han resultado decisivos en el impulso de una iniciativa en favor de los objetivos de diversificación en el suministro, que pone el foco en el Mediterráneo oriental ${ }^{87}$. Estrategia que, necesariamente, se verá impulsada tras el reciente descubrimiento, anunciado por el gigante italiano de la energía, Eni, el pasado 30 de agosto de 2015, del yacimiento de gas natural más grande del Mediterráneo en las aguas territoriales de Egipto. El yacimiento, denominado Zohr, se encuentra a 1.400 metros de profundidad y presenta un potencial de 850.000 millones de metros cúbicos de gas y una extensión de 100 kilómetros cuadrados, suficientes para afrontar las necesidades de demanda interna del país durante las próximas décadas.

Esta Plataforma, en la que estarían representados todos los sectores interesados de ambas orillas del Mediterráneo, tendría asignadas distintas funciones, orientadas a favorecer

\footnotetext{
${ }^{81}$ Tampoco se hace referencia en el Punto 4, sobre el desarrollo del mercado interior y, más concretamente, en el punto 4.2 referido a interconexiones clave y proyectos críticos, la gran mayoría, situados en Europa Oriental y Suroccidental.

${ }^{82}$ Comisión: Estrategia de Seguridad Energética, 2014 ... op. cit., p. 18.

${ }^{83}$ A este respecto se puede encontrar información en distintos estudios e informes muy exhaustivos como BP Energy Outlook 2014 y 2015, World Shale Gas Resources, elaborado por la US Energy Information Agency, donde se destacan la explotación potencial de las reservas de Argelia y Egipto.

${ }^{84}$ Comisión: Estrategia de Seguridad Energética, 2014 ... op. cit., p. 18.

85 Ibid.

${ }^{86}$ European Commission, Joint Statement: Security of gas supply: the role of gas developments in the Mediterranean region, Malta, 11 July 2014, en

http://europa.eu/rapid/press-release_STATEMENT-14-222_en.htm.

${ }^{87}$ En este sentido, se recomienda la lectura de: De Micco, Pasquale: "The prospect of Eastern Mediterrranean gas production: an alternative energy supplier for the EU?", European Parlament, Directorate General for External Policies, (Abril, 2014), en http://www.europarl.europa.eu/RegData/etudes/briefing_note/join/2014/522339/EXPOAFET SP(2014)522339 EN.pdf.
} 
la convergencia de políticas nacionales energéticas, promover inversión upstream, impulsar el desarrollo de infraestructuras de interés común, incentivar la cooperación tecnológica, examinar los mecanismos del sistema de precios..., medidas e iniciativas al servicio de la promoción de la seguridad energética regional.

Esta propuesta inicial sería ampliada en la Conferencia del Alto Nivel, dentro del marco de la Asociación Euromediterránea de la Energía, celebrada en Roma, el 19 de noviembre de 2014, donde se abordaron temas de crucial importancia ${ }^{88}$ como la promoción de un hub mediterráneo; la exploración y explotación de hidrocarburos en el Mediterráneo (ampliado); el reforzamiento del potencial del GNL como alternativa de diversificación; el establecimiento de mercados de la electricidad, regionales y subregionales, además de la promoción de energías renovables y medidas de eficiencia energética en la región.

Entre las medidas más concretas, precisamente, cabe destacar la propuesta de crear, dentro del marco de la Unión por el Mediterráneo, tres plataformas temáticas (Gas, Electricidad, Renovables y Eficiencia Energética), que faciliten y promuevan el diálogo permanente y de alto nivel, con el fin de establecer los mecanismos, iniciativas y actuaciones específicas, al servicio de los recurrentes objetivos, como: el reforzamiento en la seguridad en el suministro del gas y en los intercambio regionales; establecimiento de mercados interconectados de electricidad; despliegue efectivo de energías renovables y tecnologías de eficiencia energética, marcos viables para atraer inversiones... De nuevo, los mismos objetivos, similares peticiones y llamamientos, pero compartimentados en torno a tres especialidades temáticas, con una impronta intergubernamental de alto nivel.

En respuesta a estas directrices, el pasado 11 de junio del presente año 2015, Miguel Arias Cañete, Comisiario de Clima y Energía, junto a Yousef Bataineh, embajador de Jordania en Bélgica, así como los representantes de la UpM, anunciaban la puesta en marcha la primera de las tres plataformas: la Plataforma Euromediterránea del Gas ${ }^{89}$. Está por ver si el discurso y las expectativas generadas aterrizan en el campo de las actuaciones concretas, viables, inclusivas, bidireccionales y multidimensionales, que atraigan, esta vez sí, un potente flujo de inversiones que permitan la conversión de objetivos recurrentes en realidades concretas.

\subsection{Focalizando en el Mediterráneo Occidental: iv la importancia de África del Norte?}

En este amplio tablero geopolítico, geoeconómico: energético, ¿qué lugar ocupa el Mediterráneo Occidental?; más concretamente: ¿qué papel desempeñan Marruecos, Argelia, Túnez, Libia y Egipto, susceptibles de diversas agrupaciones (países del Norte de África; países del Magreb; países de la ribera Sur del Mediterráneo; países MENA (Middle East and North Africa), y, por tanto, protagonistas/destinatarios de diferentes (y acumuladas) políticas, medidas, iniciativas e instrumentos de geometría variable, en desmontables escenarios geográficos, en función de distintas dinámicas, variables e intereses geopolíticos; en definitiva: ¿cuál es la relevancia de estos cinco países en el marco más amplio de las relaciones energéticas euromediterráneas, insertas, a su vez, en el cambiante escenario global de la energía?

La orilla norte y la orilla sur del Mediterráneo, donde se sitúan estos cinco países del Norte de África, son interdependientes. Mientras que el mercado europeo representa el

\footnotetext{
${ }^{88}$ FINAL STATEMENT of the Italian Presidency of the EU and of the European Commission, HIGH LEVEL CONFERENCE: "Building a EuroMediterranean energy bridge: the strategic importance of euromed gas and electricity networks in the context of energy security", Rome, 19 November 2014.

${ }^{89} \mathrm{En}$ : http://www.energynews.es/se-pone-en-marcha-la-plataforma-de-gas-euromediterranea-uno-de-los-ejes-dela-politica-energetica/.
} 
principal destino de las exportaciones ${ }^{90}$ de estos países, la UE depende de las importaciones de hidrocarburos procedentes de la región ${ }^{91}$. De hecho, durante décadas, la energía viene constituyendo el principal vínculo de interdependencia entre la UE y los cinco países del Norte de África, proporcionando, según los casos, seguridad en la demanda o seguridad en el suministro, siempre de forma constante, a pesar de la permanente inestabilidad social y política, agravada por los acontecimientos y consecuencias de la Primavera Árabe, que caracteriza a la región. Y, es que, a pesar de los retos, los desafíos e incertidumbres que condicionan el desarrollo de las relaciones entre las dos orillas, la red de interdependencia sigue expandiéndose al compás de una dinámica en la que se entrecruzan los intereses geopolíticos y geoeconómicos de los actores implicados, sometidos a importantes condicionantes de distinta naturaleza, en un proceso de permanente intercambio de flujos energéticos $^{92}$, que define la dinámica global de la energía.

En principio, la proximidad geográfica de los países del Norte de África; la condición de proveedores de hidrocarburos de Argelia, Libia y Egipto, que acumulan importantes reservas $^{93}$; la importancia estratégica de Túnez y Marruecos como países de tránsito; además del potencial de explotación de energías renovables, fundamentalmente solar y eólica, sitúan a la región como prioridad estratégica en el panorama geoenergético del Mediterráneo, en favor de la estrategia de diversificación de la UE.

Sin embargo, a pesar de las estrechas relaciones de interdependencia energética ${ }^{94}$, la UE ha mostrado su incapacidad, a lo largo de 20 años, para incorporar a sus socios del Norte de África en el desarrollo de una integración energética (intrarregional e interregional) que dé paso, tanto a la vertebración económica de los países de la región ${ }^{95}$, como al incremento de la seguridad en el suministro de la UE, reduciendo, así, los marcadores de dependencia energética respecto de Rusia. La miríada de iniciativas lanzadas por la UE desde 1995, con la puesta en marcha del Proceso de Barcelona, han mostrado evidentes limitaciones en la consecución de ambos objetivos.

En este sentido, la Iniciativa del Anillo Energético Mediterráneo de la Asociación EuroMediterránea, creada en el Proceso de Barcelona, al servicio de una aproximación multilateral hacia la región con el objetivo de promover el desarrollo de las interconexiones eléctricas de

\footnotetext{
${ }^{90}$ Exportaciones energéticas para el caso de los países productores de hidrocarburos: Argelia, Libia y Egipto, cuyos datos serán comentados más adelante. Marruecos y Túnez son considerados como países importadores de energía.

${ }^{91}$ El país proveedor más importante para la UE es Argelia, que, como vimos, ocupa el tercer lugar en la lista de proveedores gasísticos de la UE, después de Rusia y Noruega.

92 Segoviano Monterrubio, Soledad (2011): España ante el reto de la seguridad energética. Fundación Alternativas, Madrid, pp. 55-56, en:

http://www.fundacionalternativas.org/public/storage/opex documentos archivos/cf5b5c05c3b6ad60bccafb513e 7dcf0a.pdf.

${ }^{93}$ Indeo, Fabio: "La geopolítica de la energía en la región mediterránea. Necesidades regionales, seguridad logística e interdependencia. Una visión prospectiva", p.12, en: IEEE, CESEDEN, CEMISS (2014): Geopolítica de la energía en la región mediterránea, en: http://www.ieee.es/Galerias/fichero/docs trabajo/2014/DIEEET032014 GeopoliticaEnergiaRegionMediterranea.pdf; antes de la Primavera Árabe, Argelia, Libia y Egipto producían 4,1 millones de barriles de petróleo al día y 160 mil millones de metros cúbicos de gas.

${ }^{94}$ Bahgat, Gawdt: "The new emerging energy landscape: the EU and North Africa", IEMed Mediterranean Yearbook, 2015, pp. 3-6, en:

http://www.iemed.org/observatori/arees-danalisi/arxiusadjunts/anuari/med.2015/IEMed_MedYearbook2015_The\%20New\%20Emerging\%20Energy\%20Landcape_Ga wdat $\% 20$ Bahgat.pdf.

${ }^{95}$ Marín Quemada, José María y Escribano Francés, Gonzalo: "Plan Solar Mediterráneo y la intergración energética euromediterránea", Revista de Economía Industrial, no 377 (2010), p. 118, en http://www.minetur.gob.es/Publicaciones/Publicacionesperiodicas/EconomiaIndustrial/RevistaEconomiaIndustri al/377/118.pdf.
} 
la cuenca mediterránea; la Política Europea de Vecindad, de 2004, en favor la cooperación energética y la convergencia normativa sobre la base de la cooperación bilateral entre la UE y los países del sur del Mediterráneo, a través de los denominados Planes de Acción ${ }^{96}$; la Unión por el Mediterráneo, de 2008, fundamentada en un cambio de filosofía, basado en la construcción de proyectos comunes, dentro de un marco intergubernamental, donde la energía, y más concretamente, el Plan Solar Mediterráneo ${ }^{97}$, se concebía como proyecto prioritario para explotar las complementariedades entre ambas orillas del Mediterráneo, en materia de explotación de energías renovables para la generación de electricidad exportable en dirección Sur-Norte; la Asociación Euro-Mediterránea de la Energía, también con prioridad en el impulso y desarrollo de las energías renovables, de acuerdo con las directrices de la COM (2011) 539, sobre abastecimiento energético y cooperación internacional ${ }^{98}$; o iniciativas más técnicas y reguladoras como el Mercado Euro-Árabe del Gas del Mashreq (EAGM I y II), el Programa de Integración del Mercado Euromediterráneo de la Energía (MED-EMIP), Eficiencia Energética en el Sector de la Construcción (MED-ENEC I, II), o el establecimiento de la Asociación de los Reguladores de la Energía del Mediterráneo (MEDREG), reforzada con la puesta en marcha de la plataforma de coordinación de las actividades de los operadores mediterráneos de transmisión de sistemas (MED-TSO)... Distintos mecanismos, amplio abanico de iniciativas que, además de dejar constancia del dinamismo que define las relaciones energéticas entre las dos orillas, vienen a poner de manifiesto los serios desajustes entre la multitud de iniciativas y el progreso real de una efectiva integración física intra/interregional y, en definitiva, las limitaciones y carencias de la política energética exterior de la UE hacia el Norte de África. Pero: ¿qué razones explican esta dialéctica?

\section{Nueva aproximación al Mediterráneo Occidental: Propuestas para una nueva agenda europea de seguridad energética hacia la región}

\subsection{Variables en la interdependencia energética: datos relevantes para la elaboración de una nueva agenda}

\subsubsection{Intercambios energéticos euromediterráneos}

Analicemos, en primer lugar, algunos datos de intercambio energético que intervienen en la ecuación euromediterránea de la energía ${ }^{99}$. En $2012^{100}$, el consumo total de energía primaria en la región se elevó a 164 millones de toneladas equivalentes de petróleo (Mtoe), gracias a la aportación principal de los combustibles fósiles. De los cincos países, Egipto, con 84 Mtoe, y Argelia, con 46 Mtoe, son, con diferencia, los principales consumidores de energía, frente a Libia, Marruecos y Túnez que consumieron 11, 15 y 8 Mtoe, respectivamente. A su vez, Argelia, Egipto y Libia, en calidad de productores, muestran una fuerte dependencia respecto de los combustibles fósiles para la generación de electricidad. Destaca el caso de Argelia, donde el gas natural contribuye con un $95 \%$. En el caso de Egipto, el gas natural aporta un

\footnotetext{
${ }^{96}$ Planes de reforma política y económica a corto plazo, que se mueven más en el ámbito de las aspiraciones que en las medidas concretas y factibles, financiados con el Instrumento Europeo de Vecindad y Asociación (IEVA)

${ }^{97}$ Quemada y Escribano: "Plan Solar...", op. cit.

${ }^{98}$ COM (2011) 539, p. 7.

${ }^{99}$ Colombo, Silvia y Sartori, Nicolo: "Rethinking EU energy policies towards the Southern Mediterranean region", Istituto Affari Internazionalli, Working Paper, (2014), p. 3, en

http://www.iai.it/sites/default/files/iaiwp1414.pdf

${ }^{100}$ De acuerdo con la tabla elaborada en Ibid., p. 4.
} 
$70 \%$, frente al $20 \%$ del petróleo. Este último combustible escala al $70 \%$ en el mix eléctrico libio $^{101}$.

En cuanto a Marruecos, la generación de electricidad proviene, en un $70 \%$, de la energía térmica obtenida de la combustión de hidrocarburos, mientras que, en torno al $18 \%$, se importa desde España ${ }^{102}$. Las energías renovables aún tienen un peso muy reducido, aunque el objetivo del Gobierno es que, para el año 2020, el porcentaje de energía eléctrica procedente de energías renovables pase a alcanzar un $42 \%$ del total, de acuerdo con las previsiones del IEVA, $2010^{103}$. En cuanto al mix eléctrico de Túnez, es similar al de Argelia, con un $90 \%$ de aportación de gas natural. Precisamente, para reducir su dependencia energética respecto del gas y el petróleo, Túnez ha venido emprendiendo medidas concretas como PROSOL Túnez, de 2005, el Plan Solar Nacional de 2009, o la iniciativa privada TuNUR, en $2011^{104}$.

En lo que se refiere a los intercambios energéticos intrarregionales de petróleo y gas, pueden ser calificados de irrelevantes, si atendemos a las cifras que ilustran los flujos de exportación de los países productores dirigidos a los mercados internacionales de la energía y, más concretamente, a los mercados energéticos europeos. En el caso de Argelia, cerca del $72 \%$ de las exportaciones de crudo es enviado a Europa, mientras que América y AsiaPacífico, absorben el 18\% y 10\%, respectivamente; en cuanto al mercado del gas, las cifras aumentan considerablemente, ya que, entre 2012 y 2013, nada menos que el $90 \%$ de las exportaciones de gas natural argelino se dirigieron al abastecimiento de los mercados europeos (UE y Turquía): 34\%, España; 27\% Italia; 12\%, Francia; 9\%, Turquía; y, 7\% otros países europeos ${ }^{105}$. Este intenso volumen de exportación representa, sin embargo, el $13 \%$ de las importaciones de la UE ${ }^{106}$, cuya estrategia de suministro se encuentra más diversificada. Asimismo, en 2013, Europa absorbió el $75 \%{ }^{107}$ de las exportaciones de crudo libio, lo que se traduce en un limitado $8 \%{ }^{108}$ de las importaciones europeas. En cuanto a Egipto, la UE fue el destino del $56 \%$ de las exportaciones de crudo; mientras que para el caso del gas natural, cabe destacar el continuo descenso en el volumen de exportaciones desde 2009, como consecuencia del constante incremento en la demanda interna, acompañado con un descenso en la producción. Las aportaciones del gas egipcio a los mercados de la UE son meramente simbólicas, ya que, en 2013, sólo se suministró un 7\% de las exportaciones de GNL, mientras que los mercados asiáticos concentraron un volumen de exportación superior al $80 \%{ }^{109}$. El Arab Gas Pipeline (AGP), se orienta al abastecimiento de Israel, Jordania, Líbano y Siria.

101 Energy Information Agency (EIA): Country Analysis Brief: Algeria,/ Egypt/ Libya en http://www.eia.gov/beta/international/analysis.cfm. También se recomienda la consulta de:

CIEMAT (Project coordinator): Bringing Europe and third countries closer together through renewables energies: BETTER, D 7.3: Action Plan for Renewable Energy Cooperation between North Africa and EU Members States, (May 2015), pp. 13-17, en: https:/ec.europa.eu/energy/intelligent/projects/en/projects/better.

${ }^{102}$ Amegroud, Tayeb: "Morocco's power sector transition: achivements and potentials", Istituto Affari Internazionali, (2015), p.9, en: http://www.iai.it/sites/default/files/iaiwp1505.pdf.

${ }^{103}$ UE, Instrumento Europeo de Vecindad y Asociación (IEVA): Paving the way for the Mediterranean Solar Plan. National Road Map: Morocco, IEVA 2010/248-486, Febrero de 2012, p.2, en: http://www.pavingthewaymsp.eu/index.php?option=com_downloads\&task=download\&id=32.

ICEX (2014): El mercado de las energías renovables en Marruecos, p. 7, en

http://internacional.ivace.es/dms/estudios/informacion_paises/MARRUECOS-Energ-as-

RenovablesICEX2012/marruecos\%20renovables\%20icex2013.pdf.

${ }^{104}$ Indeo, Fabio: "La geopolítica..", op. cit., pp. 33-36.

105 EIA, Country Analysis, op. cit.

${ }^{106}$ EU, Statistical Pocketbook 2014, p. 27.

${ }^{107}$ EIA, Country Analysis, op. cit.

${ }^{108}$ EU Statistical Pocketbook, 2014, op. cit., p. 27.

${ }^{109}$ EIA, Country Analysis op. cit. 


\subsubsection{Interconexiones intrarregionales de gas y electricidad y flujo de inversiones}

En cuanto a las interconexiones de gas y electricidad entre los países del Norte de África resultan claramente insuficientes. Según el Informe MedREG de 2015 sobre Internconexión de Infraestructuras en el Mediterráneo ${ }^{110}$ estas interconexiones deben ser sustancialmente mejoradas con el fin de garantizar el desarrollo efectivo de un mercado regional de la energía, que contribuya a impulsar el despegue económico de la región. En lo que se refiere a las infraestructuras existentes de electricidad, Marruecos, Argelia y Túnez se encuentran interconectados a través de transmisiones de alto voltaje; asimismo, Marruecos está conectado a España y, a su vez, los tres países se encuentran sincronizados con la red de alto voltaje de la UE ${ }^{111}$.

Sin embargo, el comercio de electricidad entre los tres países se mantiene en niveles mínimos, teniendo en cuenta las variables de proximidad geográfica y disponibilidad de recursos. La Tabla 1 resulta ilustrativa para comprobar el promedio de utilización de las interconexiones, así como la energía intercambiada en Gigawatios hora al año ${ }^{112}$.

La tensión transfronteriza en la región, como consecuencia de los impactos derivados de la Primavera Árabe y del conflicto no resuelto del Sáhara Occidental, representan la causa latente de las tensiones que enfrentan a los países del Magreb, paralizando los potenciales de desarrollo económico y progreso en la región con un evidente impacto en la dimensión de la seguridad. Estos problemas subyacen en la falta de diálogo y entendimiento político entre las partes implicadas, especialmente Marruecos y Argelia, alimentando, constantemente el clima de desconfianza política que dificulta la consecución de los objetivos de integración regional, emprendidos por la UE, con el fin de mejorar la red de infraestructuras de transporte y energéticas, cuya situación de precariedad repercute de forma negativa en los intercambios intrarregionales.

\begin{tabular}{|c|c|c|c|}
\hline Interconnection & $\begin{array}{c}\text { Max transfer capacity } \\
\text { (MW) }\end{array}$ & $\begin{array}{c}\text { Energy exchanged } \\
\text { (GWh/Year) }\end{array}$ & $\begin{array}{l}\text { Load factor } \\
(\%)\end{array}$ \\
\hline Spain-Morocco & 700 & 4227 & 69.0 \\
\hline Morocco-Spain & 700 & 15 & 0.2 \\
\hline Morocco-Algeria & 400 & 613 & 17.0 \\
\hline Algeria-Morocco & 400 & 662 & 19.0 \\
\hline Algeria-Tunisia & 150 & 141 & 11.0 \\
\hline Tunisia-Algeria & 150 & 122 & 9.0 \\
\hline Libya-Egypt & 180 & 152 & 10 \\
\hline Egypt-Libya & 180 & 70 & 4 \\
\hline Egypt-Jordan & 450 & 363 & 9 \\
\hline Jordan-Egypt & 200 & 9 & 1 \\
\hline Egypt-Palestine & 17 & 134 & 90 \\
\hline Jordan-Palestine & 20 & 158 & 90 \\
\hline Jordan-Syria & 350 & 69 & 2 \\
\hline Syria-Jordan & 200 & 20 & 1 \\
\hline Turkey-Syria & 250 & 97 & 4 \\
\hline
\end{tabular}

Fuente: MedREg.

\footnotetext{
110 Mediterranean Energy Regulators (MEDREG): Interconnetin infraestructures in the Mediterranean: a challenging environmet for investments (2015), pp. 5-6, en http://www.medreg-regulators.org/Portals/45/questionnaire/INV report final.pdf. ${ }^{111}$ Ibid., p. 11.

112 Ibid., pp. 11-12. MEDREG utiliza los datos del estudio titulado: Infraestructures and sustainable energy development in the Mediterranean, publicado en 2010, y conocido como Plan Bleu.
} 


\subsubsection{Interconexiones eléctricas}

La Tabla 2 resulta especialmente ilustrativa para visualizar el horizonte de inversiones en infraestructuras de interconexión eléctrica a corto, medio y largo plazo para los países del Mediterráneo. A excepción de Egipto, orientado al Mediterráneo oriental, y teniendo en cuenta los recientes hallazgos de los yacimientos de gas, no aparece ningún país del Norte de África como destinatario de estos flujos, ni en el corto (2014-2019); ni en el medio (20192024); ni en el largo plazo, contemplado para inversiones en proyectos más allá del 2024. Esta planificación pone en riesgo los proyectos de futuro de las renovables, ante la carencia de inversiones que modernicen y refuercen las redes domésticas y las infraestructuras de conexión transfronteriza (entre los países de la región y hacia los mercados de la UE) con el fin de integrar la energía procedente de las renovables en un sistema eléctrico caracterizado por su limitada capacidad ${ }^{113}$. La falta infraestructuras de interconexión horizontales y verticales hace previsible que, a medio y largo plazo, previa reestructuración y reforma de las redes eléctricas nacionales magrebíes, la energía que pueda ser extraída de la explotación progresiva de las renovables sea orientada, de forma prioritaria, cuando no, exclusiva, a cubrir las necesidades de demanda interna de los países del norte de África y no tanto a la exportación de electricidad verde, que proyectan iniciativas como el Plan Solar Mediterráneo.

Tabla 2
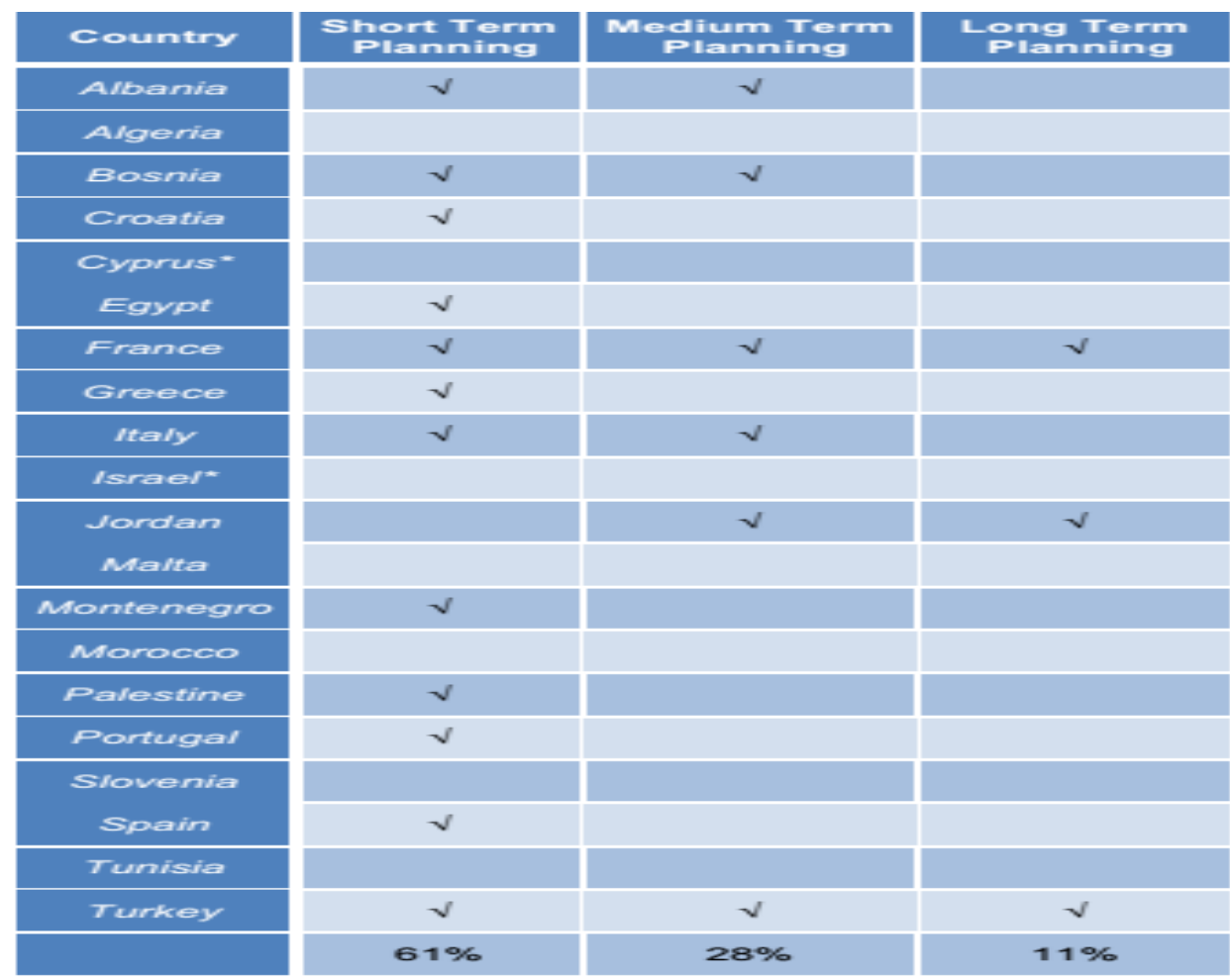

Fuente: MedReg.

\footnotetext{
${ }^{113}$ Marruecos, con una red de infraestructuras aceptable, una economía diversificada y un desarrollado sector bancario, es el país más atrayente para las inversiones en energías renovables. De todos modos, excepto Libia, todos los países del norte de África han desarrollado sus planes nacionales, los denominados Planes de Acción para las Energías Renovables. Un estudio comparativo de todos los países sobre los objetivos contenidos en estos planes, los procesos de reforma en el sector energético, así como las políticas reguladoras emprendidas, pueden consultarse en el Proyecto BETTER, op. cit., p. 21.
} 


\subsubsection{Interconexiones gasistas}

En cuanto al gas, las interconexiones en la región se vertebran sobre el eje vertical Sur-Norte (gasoductos Magreb-Europa, Medgaz, Transmed y Greenstream), orientado a garantizar la seguridad en el suministro europeo, apenas, sin líneas horizontales de interconexión entre los países de la ribera sur y, más concretamente, entre los países del Norte de África (véase Figura 4).

Figura 4

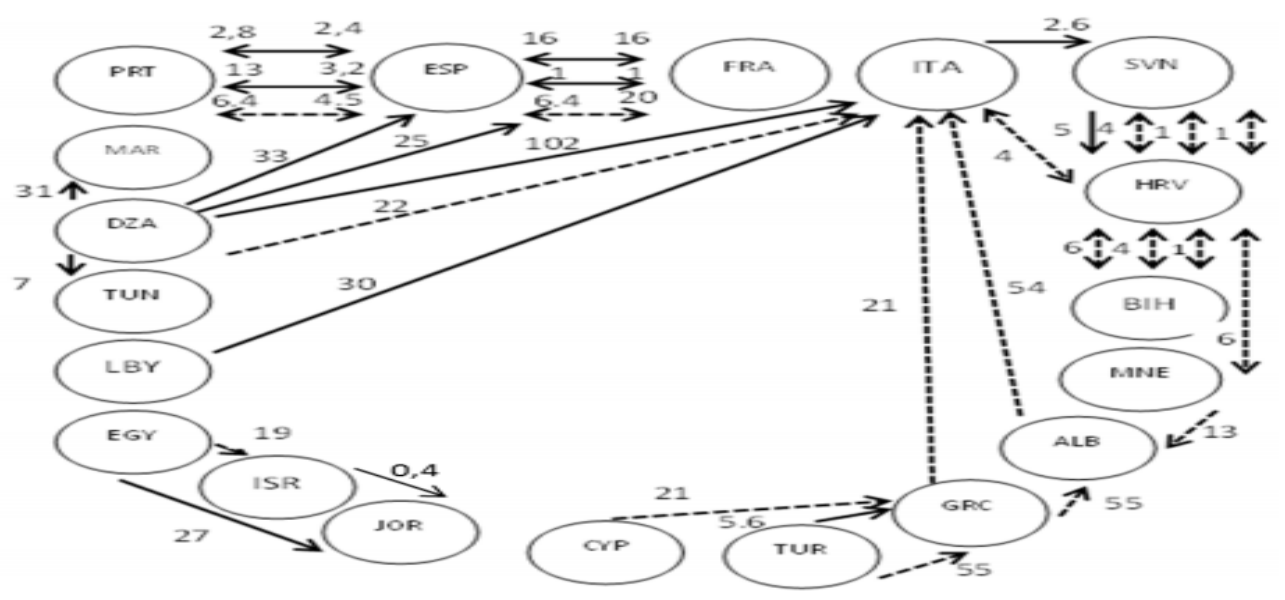

Esta figura nos permite visualizar las interconexiones, existentes y futuras, de gas ${ }^{114}$, donde se constatan cinco realidades, que ponen en evidencia la retórica del discurso sobre la importancia estratégica del Norte de África: 1) la incuestionable importancia del mencionado eje Sur-Norte, como línea de exportación/suministro de los países productores del Norte de África hacia la UE, haciendo patente la alarmante concentración del flujo de las exportaciones magrebíes; 2) la proyección de futuro del Mediterráneo oriental, en conexión con el Corredor Sur del Gas, con la previsible explotación de las bolsas de hidrocarburos en la denominada Cuenca del Levante, tras los descubrimientos en Chipre, Israel y Egipto, y el aumento de la demanda energética de los países balcánicos; 3 ) la progresiva consolidación de Italia como país de tránsito hacia los mercados de la UE (centro y norte de Europa); 4) la relevancia, a medio, incluso a largo plazo, de la aportación de los combustibles fósiles en el mix energético de los países de las dos orillas del Mediterráneo, dadas las infraestructuras gasísticas proyectadas; y, 5) la insignificancia de las interconexiones horizontales entre los países del Norte de África (actuales y a largo plazo), poniendo en riesgo los avances hacia la integración energética necesaria para impulsar el desarrollo económico de la región y allanar el camino de transición hacia un escenario de descarbonización. Esta figura se complementa con las siguientes del Mediterráneo:

\footnotetext{
${ }^{114}$ Para una explicación más detallada sobre las interconexiones de gas, existentes y futuras, consultar MedReg, pp. 25-32.
} 
Figura 5: Mediterráneo Occidental

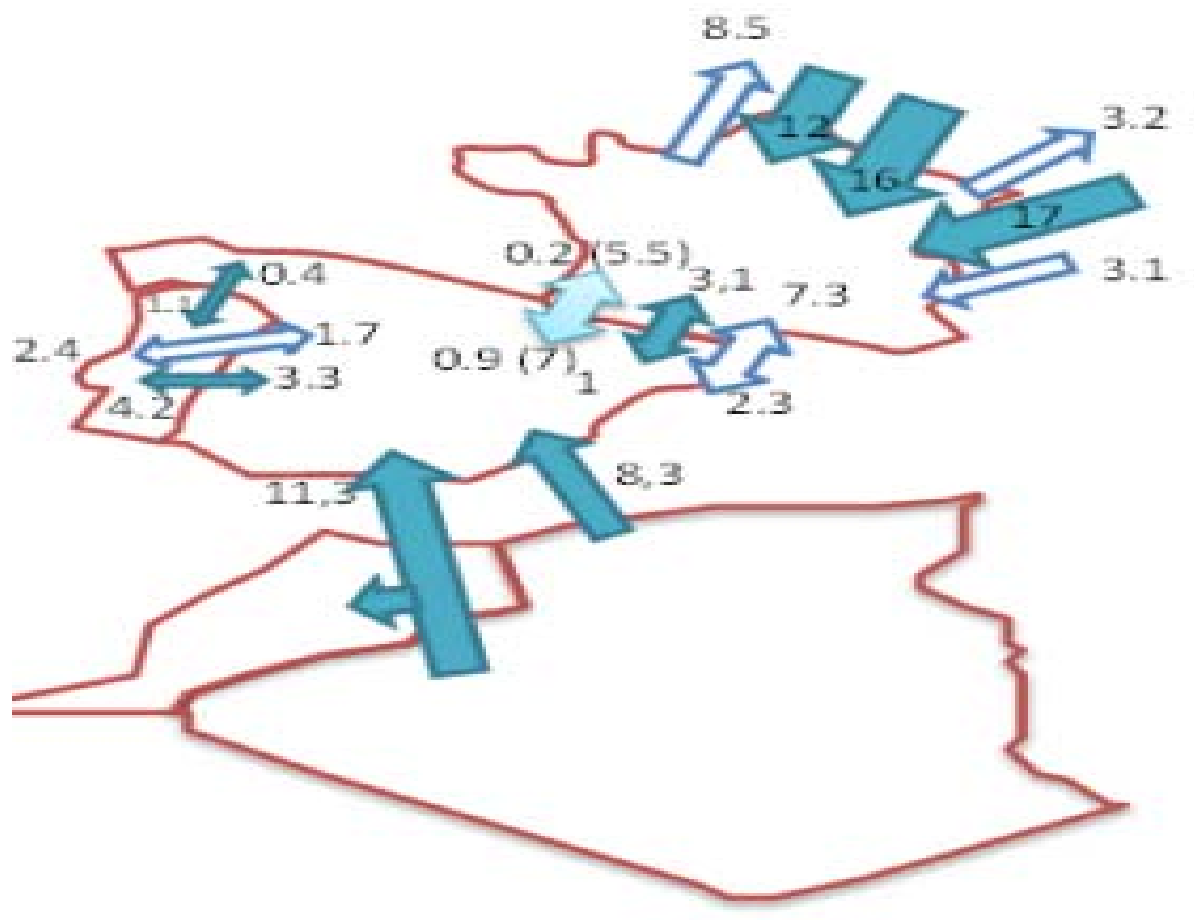

Fuente: MedReg.

$\longrightarrow$ Future

Upgrade

Figura 6: Mediterráneo Central

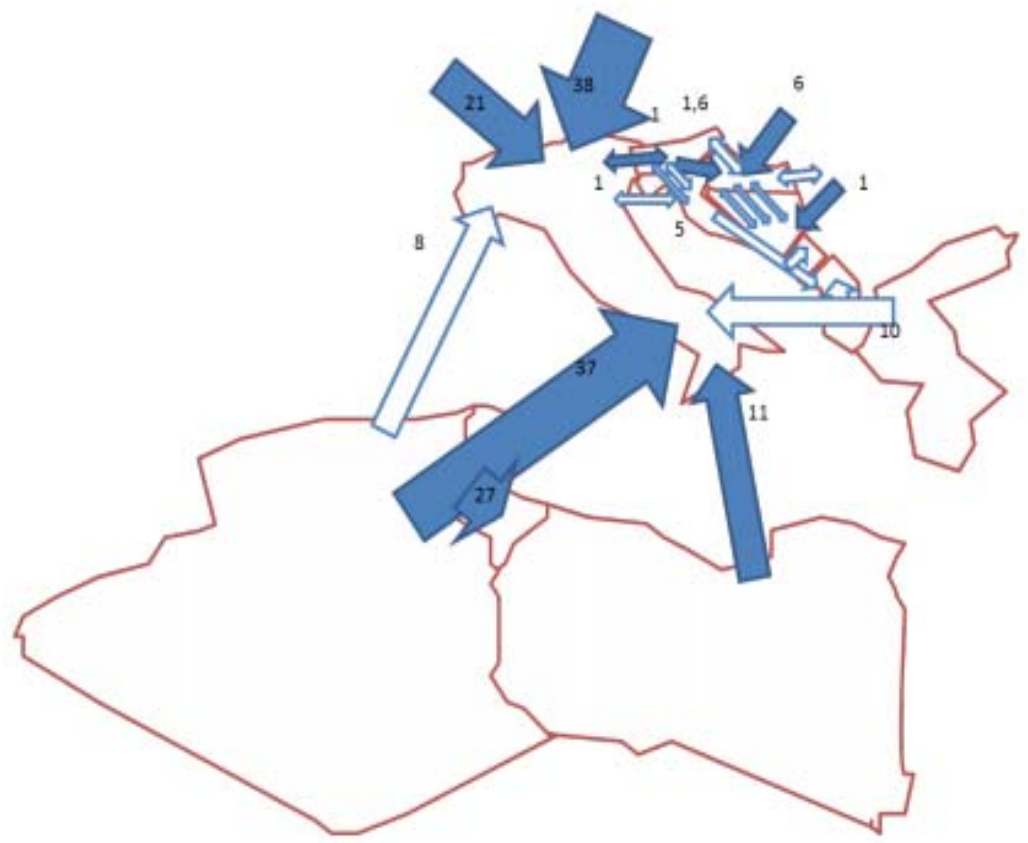

Fuente: MedReg. 
Figura 7: Mediterráneo Oriental

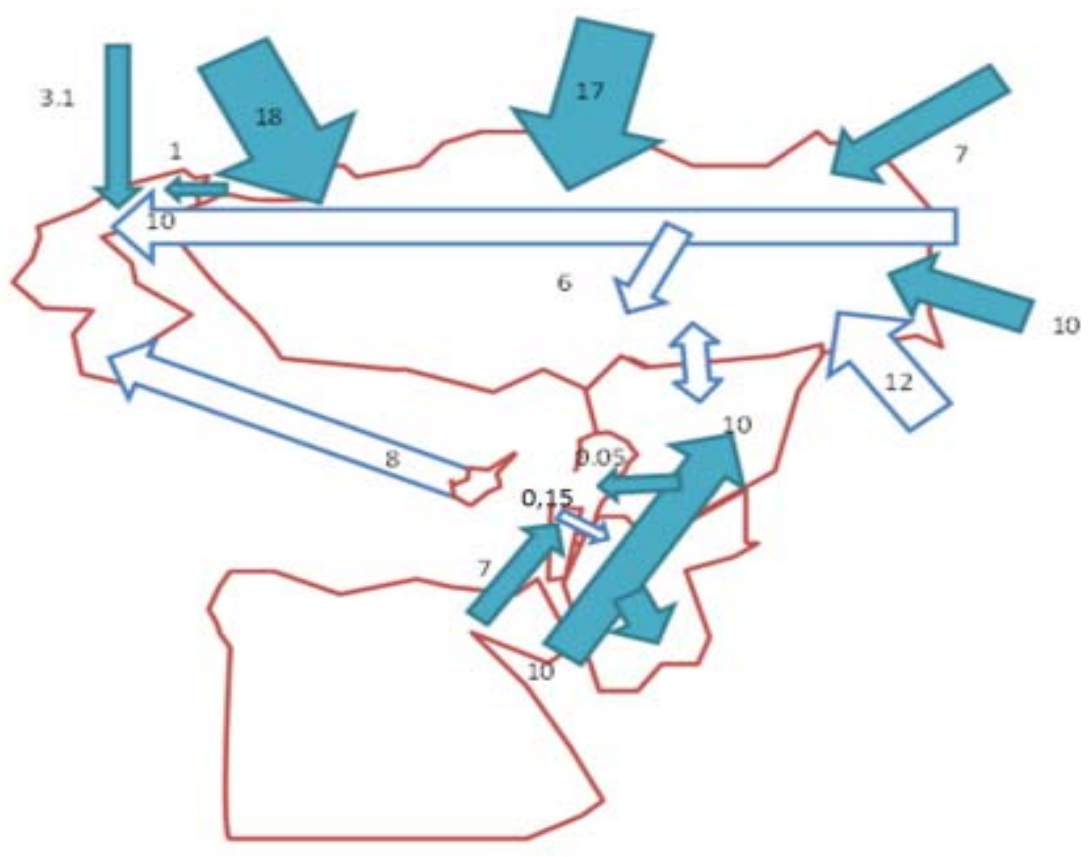

Fuente: MedReg.

Así, mientras el discurso europeo persiste en la importancia estratégica de la cooperación energética euromediterránea sobre la base del reconocimiento mutuo, los datos analizados ponen de relieve los desequilibrios en los ejes Norte-Sur/Oeste-Este, además de la situación de extrema dependencia y vulnerabilidad de los países del Norte de África, respecto de los combustibles fósiles para la generación de electricidad, y respecto de los mercados energéticos de importación europeos que, a pesar del descenso en el consumo, aún concentran el $75 \%{ }^{115}$ de las exportaciones de hidrocarburos, que garantizan el flujo de divisas hacia las arcas de los Estados productores magrebíes, no incentivados a emprender estrategias exitosas de diversificación en las exportaciones y fuentes de energía.

Los datos proyectan, además, un escenario de cooperación magrebí bajo mínimos, que viene a sumarse, o quizás, es el resultado de la tensión transfronteriza que vive la región, como consecuencia, entre otros factores, del conflicto no resulto del Sáhara Occidental, causa latente de las malas relaciones entre Marruecos y Argelia; así como de los complejos procesos derivados de la Primavera Árabe, para los casos de Libia, Egipto y Túnez, con alarmantes repercusiones transregionales en el Sahel, Oriente Medio y Europa.

\subsection{Necesidad de nuevos enfoques}

\subsubsection{Búsqueda de equilibrios}

La cooperación energética intrarregional e intermediterránea, esta última en condiciones de cierto equilibrio entre las dos áreas del Mediterráneo ampliado, occidental y oriental, constituye un objetivo estratégico prioritario al servicio, no sólo, de los intereses de seguridad europeos y, más concretamente de seguridad energética, sino en favor de la consolidación de los frágiles procesos de transición política, económica y social emprendidos por los países del

\footnotetext{
${ }^{115}$ Colombo y Sartori: "Rethinking...", op. cit., p. 7.
} 
Norte de África, con claras consecuencias a escala global, en un mundo interdependiente e interconectado.

Este objetivo prioritario se encuentra, aparentemente, bien identificado por todos los actores involucrados en el proceso, en todos los niveles: altas instancias y sociedad civil; desde distintas aproximaciones: top-down/ bottom-up. En ambas orillas. Son muchos años, distintos enfoques, un largo proceso; en definitiva, un complejo entramado de medidas, marcos, diálogos, asociaciones, programas, instrumentos, recursos, plataformas, reuniones, relaciones (formales/informales)..., construidos en torno al mismo objetivo, la misma y, aparentemente, inalcanzable meta. Sorprende que tantos mecanismos, esfuerzos y recursos arrojen un balance tan pobre, escaso, (frustrante) de resultados. Un balance, definido por la parálisis y el bloqueo en el camino hacia la integración energética de los países del Norte de África.

\subsubsection{Configuración de una matriz estratégica alternativa respecto del epicentro que supone} Rusia

¿Qué obstáculos impiden la articulación de una matriz estratégica eficaz sobre la que se vertebren, de forma coordinada y equilibrada, nuevas fórmulas, soluciones viables, incentivos bidireccionales, capaces de integrar éxitos y fracasos de anteriores procesos, en el camino hacia la integración regional energética en horizontes de futuro, a medio y largo plazo? Sin desajustes entre la retórica del discurso europeo y la realidad de sus actuaciones, en la medida que se pretende atribuir la categoría de prioridad estratégica a un objetivo de la vecindad del sur, de los países del Norte de África, que no consigue despegar de su condición de mero objetivo secundario, postergado, mil veces retomado, frente a la relevancia del área de vecindad del este, derivada de la persistencia geopolítica europea por penetrar en el área de influencia rusa en su estrategia de diversificación de suministros.

\subsubsection{Conexión del paradigma de securitización geopolítico y normativo con las realidades políticas, económicas, sociales y medioambientales}

Una de las explicaciones se encuentra en el enfoque adoptado por la UE para abordar las relaciones energéticas euromediterráneas. $\mathrm{Y}$, es que, la concepción estratégica europea viene definida por la centralidad de las prioridades relacionadas con la seguridad, tanto en su dimensión estratégica, militar y operativa, (control migratorio y de fronteras; lucha contra el terrorismo y el crimen organizado, impactos relacionados con la pobreza energética; o, el acceso seguro a fuentes de energía); como en su dimensión jurídica, legal y normativa, al servicio del establecimiento de marcos reguladores, claros, seguros y estables, que garanticen la viabilidad y los retornos de las ingentes cantidades de capital, que requieren las inversiones en infraestructuras energéticas a largo plazo en entornos geopolíticos inestables como en el Norte de África. Lo que implica que la UE contemple sus intereses energéticos en la región desde una perspectiva geopolítica y normativa, desvinculada de pilares tan relevantes como el desarrollo económico y social; o el buen gobierno de la energía, en relación con los impactos medioambientales.

La importancia de ambos enfoques, geopolítico y normativo, dentro de la estrategia de securitización europea resultan cruciales ${ }^{116}$, además de necesarios, en el desarrollo de las

\footnotetext{
${ }^{116}$ La energía representa uno de los sectores estratégicos más relevantes para la seguridad en cualquier país, teniendo en cuenta que actores no estatales violentos ya han demostrado que los atentados contra infraestructuras energéticas se encuentran entre sus objetivos prioritarios. Los ataques contra gasoductos, oleoductos o petroleros vienen aconteciendo en distintas partes del mundo, Rusia, Pakistán, Turquía, e, igualmente, en países del Norte de África como Argelia, Libia y Egipto. Ver: Giroux, Jennifer: "Energy infraestructura targeting in the Mediterranean: a shifting threat terrain", IEMed Mediterranean Yearbook 2015, en
} 
relaciones energéticas euromediterráneas; sin embargo, ambas aproximaciones deben profundizar su conexión con las realidades políticas, económicas, sociales y medioambientales de la región; y hacerlo, sobre la base de la interrelación de tres dinámicas, interna, regional y global ${ }^{117}$, que interactúan en el corto, medio y largo plazo. Sólo de este modo, se podrán identificar, con cierto grado de certidumbre, los obstáculos, barreras y resistencias que dificultan el camino de la complementariedad existente entre ambas orillas, entre los países del Norte de África. Sólo de esta forma, se podrán identificar, a la vez que explotar, las sinergias energéticas que permitan el fortalecimiento de una red de interdependencia intrarregional e intermediterránea, capaz de invertir tendencias energéticas, ya insostenibles, en la región.

\subsubsection{Inversión de las tendencias energéticas negativas en la región}

Tendencias que vienen definidas por el progresivo deterioro de las condiciones socioeconómicas de la población magrebí; las preocupantes proyecciones de crecimiento demográfico a medio plazo en la región del Norte de África, donde, entre 2011 y 2030, se prevé un incremento de población de más de 50 millones de habitantes, pasando de 167 millones en 2011, a una cifra situada en torno a los 220 millones en el horizonte de $2030^{118}$; el consiguiente impacto en el crecimiento de la demanda energética doméstica, según las previsiones $^{119}$, en torno al $70 \%$ para 2020 , con más de un $90 \%$ de aportación en combustibles fósiles, con los subsiguientes incrementos en emisiones GEI; el déficit comercial derivado de esta situación en los países importadores del Magreb y la contracción en la exportaciones de los países productores, con la consiguiente reducción en sus ingresos por divisas.

En consecuencia, los impactos negativos en las cuentas públicas, ya sobrecargadas con agresivas políticas de subsidios a los combustibles ${ }^{120}$ para mantener controladas la beligerancia social y el agravamiento de la crisis económica, que, por otra parte, resultan difícilmente controlables, ante la incapacidad de los gobiernos, como consecuencia de la escalada en el gasto público, -destinado, en gran medida, a cubrir los subsidios energéticos-, de emprender medidas de modernización y bienestar social que alivien, entre otras cuestiones, la situación de pobreza energética de poblaciones marginales urbanas y en zonas rurales. Situación que, en definitiva, viene a desincentivar la canalización de las necesarias inversiones para promover infraestructuras de interconexión horizontal en el Mediterráneo ampliado (eje oeste-este/este-oeste), cada vez más fragmentado, en un panorama energético de interdependencia global y sometido a profundas transformaciones.

\subsubsection{Aproximación basada en el pragmatismo}

Los desafíos políticos, económicos, sociales, energéticos y medioambientales, unos ya arraigados y otros más recientes como consecuencia de las dinámicas globales, exigen, en definitiva, la reevaluación de la percepción europea hacia región. Una revisión que permita

http://www.iemed.org/observatori/arees-danalisi/arxius-

adjunts/anuari/med.2015/IEMed_MedYearbook2014_Shifting_Threat_for_Energy_Infrastructure Mediterranea n Jennifer_Giroux.pdf.

${ }^{117}$ Colombo y Sartori: "Rethinking...", op. cit., pp. 9-14.

${ }^{118}$ Wai Mun Hong: "An analysis of North Africa capacity to achieve renewable energy development", Topics in the Middle Easters and African Economies, № 16, Vol.2 (September 2014), p. 234, en http://www.luc.edu/orgs/meea/volume16/pdfs/Hong.pdf.

${ }_{119}$ Bergasse, Emmanuel, et al.: "The relationship between energy and socioeconomic development in the southern and Eastern mediterranean", MEDPRO Technical Reports, № 27, (2013), p.3, en http://www.ceps.eu/system/files/MEDPRO\%20TR27 CASE\%20Bergasse \%20Energy\%20and\%20Socioeconomic\%20Development updated 15Feb2013.pdf.

${ }^{120}$ Según los datos de la IEA para 2013: 77,5\%, en Argelia; 76, 7\%, en Libia; y 61, 2\%, en Egipto, en http://www.iea.org/subsidy/index.html. 
replantear el enfoque retórico centrado en valores, -en ciertos aspectos no compartidos por nuestros vecinos del sur-, para incorporar una perspectiva más operativa, pragmática e inclusiva, focalizada en avances socioeconómicos, generadores de una sociedad civil más dinámica y productiva.

\subsubsection{Energías renovables como punto de convergencia euromediterránea en la transición} hacia la descarbonización

Lo que, a día de hoy, parece fuera de toda duda, es el consenso generalizado a escala global sobre la necesidad de persistir en la senda de transición hacia la descarbonización en horizontes de futuro. En este sentido, la explotación de las energías renovables ofrece un punto de convergencia y complementariedad en la región del Mediterráneo $\mathrm{y}$, más concretamente, entre la UE y los países del Norte de África, dado su enorme potencial en energía solar y eólica. El Anillo Mediterráneo, el Plan Solar Mediterráneo, DESERTEC, TuNur representan distintas iniciativas que responden a esta inquietud, aunque, como vimos, con escasos resultados en lo que se refiere a la materizalización de estos ambiciosos proyectos.

La UE ha dejado claro su compromiso con los objetivos de descarbonización a largo plazo, fijando el objetivo de reducción de emisiones GEI en un techo del 80-95\% para 2050, sustentado en procesos intermedios del $20 \%$ para 2020 y del $40 \%$ para 2030; por su parte, los países del Norte de África, además de disponer de extraordinarios recursos en energía solar y eólica, especialmente, Marruecos, Argelia y Libia, con más de 3000 horas de luz solar al año y extensas zonas con intensidad de viento, precisan emprender urgentemente una estrategia de diversificación de fuentes de energía que les permita reducir la fuerte dependencia en los combustibles fósiles para la generación de electricidad en un contexto de incrementos de demanda. En 2012, para el conjunto de la región, la aportación de energía renovable en el mix eléctrico de los países del Norte de África, no superó el $8 \%$, con un $7 \%$, procedente de la energía hidráulica, y el resto, en torno a un $1 \%$, de otras fuentes renovables ${ }^{121}$.

\subsubsection{Energía y clima como motor de desarrollo}

Un planteamiento donde energía y clima sean contemplados como motor de desarrollo, generadores de una reactivación económica que dinamice el mercado laboral; plataformas de oportunidad para la captación de inversiones que impulsen el crecimiento y una redistribución más justa y equitativa de la riqueza; al servicio de una gestión de los recursos menos clientelar, más transparente, más respetuosa con el entorno en el camino inapelable hacia la descarbonización.

\subsection{Opciones de convergencia energética a corto. medio v largo plazo}

En este sentido, los mutuos beneficios derivados de esta convergencia energética entre las dos orillas serían más que notables, a largo plazo. En el caso de la UE: para avanzar en la estrategia de diversificación de fuentes de energía renovable, de acuerdo con sus compromisos de descarbonización a futuro, abriendo, al mismo tiempo, una ventana de oportunidad de progreso y estabilidad en los países de la región. Y, es que, los beneficios potenciales de estas relaciones de interdependencia con la UE serían especialmente relevantes para los países del Norte de África, en la medida que, a largo plazo, la estrategia de diversificación con energías renovables les permitiría responder de forma paulatina a los incrementos de la demanda interna, reduciendo progresivamente la dependencia en los hidrocarburos para la generación de electricidad y, por tanto, las emisiones GEI; les permitiría crear un entorno de oportunidades en el mercado laboral mediante la formación de mano de

\footnotetext{
${ }^{121}$ Proyecto BETTER, op., cit., p. 15.
} 
obra cualificada ${ }^{122}$; podrían garantizar un suministro estable de electricidad en el mercado interno, gracias al incremento en las aportaciones de las renovables; estarían capacitados para impulsar estrategias de exportación de energía renovable entre los mercados del sur y hacia los mercados del norte, fortaleciendo las rutas de interconexión intrarregionales e intermediterráneas; despegarían en el desarrollo industrial, garantizando, en definitiva, la captación de inversiones que retroalimentasen el proceso, convirtiéndolo en irreversible.

El escenario de futuro descrito es ampliamente conocido por todos. Resulta relativamente sencillo trazarlo, aunque, no tanto, dotarlo de contenido. Los desafíos, por tanto, se mueven en el corto plazo. Y el primer desafío en este marco temporal es dar una debida respuesta al incremento sostenido de demanda energética en la región. Esta respuesta inicial debe estar centrada en un proceso de reforma de la política de subsidios a los combustibles $^{123}$, lo que implicaría el incremento de los precios de la energía, cuyo impacto se dejaría notar en dos frentes: por un lado, en una sensible reducción del gasto público, -que podría diversificarse hacia medidas para combatir la pobreza energética-; $y$, por otro lado, en reducciones notables del consumo energético, incrementando la eficiencia y, por tanto, la seguridad energética mediante el control de la demanda.

3.3.1. Apuesta decidida para contrarrestar los impactos negativos derivados del escenario de descarbonización

La consecuencia no deseada de este proceso se dejaría sentir, en el corto plazo, en la elevación del riesgo de inestabilidad política y social, que podría ser contrarrestado con inversiones públicas y privadas destinadas a la modernización de las infraestructuras energéticas domésticas y con programas de ayuda europeos de alto valor añadido (formación, empleo, transferencia tecnológica), gestionados, no sólo por los Gobiernos receptores, sino contando con la participación de organismos independientes en proyectos de energías renovables descentralizados locales, tanto en zonas rurales como urbanas.

\section{Conclusión}

Aunque titubeante, el camino emprendido por la UE hacia la descarbonización es irreversible frente a los incontestables desafíos del cambio climático. A largo plazo, el compromiso con esta estrategia derivará en el sustancial descenso de los consumos europeos de energía fósil, lo que, necesariamente, repercutirá en la reducción de los flujos de importaciones de hidrocarburos procedentes de la Cuenca del Mediterráneo y, en particular, de los países productores del Norte de África, cuyas estrategias energéticas, como hemos tenido la oportunidad de constatar, se caracterizan por un alto grado de concentración de los flujos de sus exportaciones hacia los mercados europeos.

Este inapelable horizonte de futuro obliga a la Unión a sentar las bases en el corto plazo para impulsar, retomar, reforzar, emprender, inventar nuevas fórmulas, medidas e instrumentos que contribuyan a amortiguar los previsibles impactos negativos en la seguridad energética de los países del Magreb que, a su vez, y de forma inevitable, acabarían por repercutir en la política energética de la Unión en su lucha contra las consecuencias del cambio climático, y por ende, en las relaciones energéticas euromediterráneas, obstaculizando, en definitiva, el camino de transición y consolidación hacia el objetivo global de la descarbonización.

\footnotetext{
${ }^{122}$ International Renewable Energy Agency (IRENA)/Renewable Energy Policy Network for the 21st Centuru (REN21): MENA Renewables Status Report 2013, en http://www.ren21.net/Portals/0/documents/activities/Regional\%20Reports/MENA_2013_lowres.pdf.

${ }^{123}$ Proyecto BETTER., p. 16.
} 
El panorama descrito exige, por tanto, reorientar, para equilibrar, la importancia estratégica que debe ser atribuida a las dos áreas del denominado Mediterráneo ampliado, occidental y oriental, con el fin de incrementar, sobre la base de una incuestionable voluntad política, el flujo de inversiones, públicas y privadas, destinadas a la reconversión climática de los países del Norte de África, precisamente, al servicio de los intereses de la Unión y de los propios países del Magreb. 